\title{
Utilização de uma nova tecnologia para o cadastro e acompanhamento de crianças de risco no município de Diadema - SP.
}

\author{
Edson Aguilar Perez
}

Dissertação apresentada ao Programa de Pós Graduação em Saúde Pública da Faculdade de Saúde Pública da Universidade de São Paulo para obtenção do título de Mestre em Saúde Pública.

Área de Concentração: Saúde, Ciclos de Vida e Sociedade.

Orientador: Prof. Dr. Arnaldo Augusto Franco de Siqueira 
5295212011

É expressamente proibida a comercialização deste documento, tanto na sua forma impressa como eletrônica. Sua reprodução total ou parcial é permitida exclusivamente para fins acadêmicos e científicos, desde que na reprodução figure a identificação do autor, título, instituição e ano da tese/dissertação. 
Com amor e gratidão dedico este estudo à minha esposa Maria Amélia e à minha filha Fernanda, pelo apoio e incentivo que delas sempre recebo. 


\section{Agradecimentos}

Ao meu orientador, professor Arnaldo Augusto Franco de Siqueira, pela boa vontade permanente e suas valiosas correções, permitindo assim a concretização deste estudo.

Ao Sr. Osvaldo Misso, ex-secretário da Saúde de Diadema, que me autorizou a criação desta ferramenta de informática e viabilizou a realização deste trabalho.

Ao Coordenador da Atenção Básica da Secretaria de Saúde de Diadema, amigo Douglas Schneider Filho, que sempre preocupado em melhorar a qualidade da atenção em saúde daquele município, compartilhou comigo do ideal deste trabalho.

À equipe de Informática da Secretaria de Saúde de Diadema, que foi parceira e sem a qual a ideia não teria se tornado realidade.

Aos funcionários da Secretaria de Saúde de Diadema que souberam entender a importância deste aplicativo e no dia-a-dia colaboram de maneira efetiva para a institucionalização desta ferramenta.

À amiga Márcia Fujiko Torigoshi, que sempre soube me incentivar nesta empreitada.

Aos amigos Leandro e Yara, demais professores e funcionários do Departamento de Saúde Materno-Infantil, pelo carinho e amizade com que me acolheram. 
E finalmente, um agradecimento especial a todas as crianças de Diadema que fizeram parte deste estudo, pedindo a Deus que, apesar dos percalços iniciais que enfrentaram, seus caminhos de vida sejam abençoados. 
Perez EA. Utilização de uma nova tecnologia para o cadastro e acompanhamento de crianças de risco no município de Diadema - SP [dissertação de mestrado]. São Paulo: Faculdade de Saúde Pública da USP; 2011.

\section{Resumo}

Introdução: A queda da mortalidade infantil ocorre em níveis distintos nos países desenvolvidos e nos em vias de desenvolvimento. A melhoria das condições sócio-econômicas aliada ao acesso a serviços de saúde de qualidade são fatores preponderantes nessa queda. A melhor utilização dos recursos da saúde, através do princípio da equidade, nos leva ao estabelecimento de critérios de risco. Os recém-nascidos e os menores de um ano que apresentam sinais de risco devem ter garantida uma assistência especial. Objetivo: demonstrar uma nova tecnologia desenvolvida com o intuito de cadastrar e acompanhar crianças de risco. Método: Foi realizado um estudo do tipo descritivo, retrospectivo, com crianças nascidas no período de $1 .^{\circ}$ de janeiro a 30 de junho de 2010 , no Hospital Municipal de Diadema, Hospital Estadual de Diadema, em outra maternidade particular do município, e em outras públicas e privadas de outros municípios. Também fizeram parte desse estudo crianças menores de um ano, egressas das enfermarias de pediatria do Hospital Municipal de Diadema, Hospital Estadual de Diadema e da do Pronto Socorro Central, neste mesmo período. Foram realizadas análises a partir de relatórios que o sistema informatizado fornece. Resultados e Discussão: Um total de 636 crianças foi inscrito no projeto, neste periodo, com uma maior porcentagem das do sexo masculino. Para os provenientes dos Berçários, a maior causa de inscrições se deveu ao baixo peso ou prematuridade e hiperbilirrubinemia. Para os provenientes das enfermarias de pediatria, as patologias respiratórias foram preponderantes. $\mathrm{O}$ acompanhamento destas crianças não se deu de maneira satisfatória. Conclusão: Apesar da importante ferramenta em que o sistema se constitui, possibilitando o cadastramento e acompanhamento adequado das crianças de risco, faz-se necessário seu monitoramento e a utilização de suas informações para o seu gerenciamento.

Descritores: Recém-nascido, Criança, Mortalidade Infantil, Risco, Sistema Informatizado, Internet. 
Perez EA. Utilização de uma nova tecnologia para o cadastro e acompanhamento de crianças de risco no município de Diadema - SP/ Application of a new technology for registration and follow-up of children under risk in the city of Diadema-SP [dissertation]. São Paulo (BR): Faculdade de Saúde Pública da USP; 2011.

\begin{abstract}
Introduction: The decrease of infant mortality rates happens in different intensities at developed and developing countries. The enhancement of socioeconomic living conditions associated with access to quality health care services are key variables to this decreasing trend. Better use of health resources, due to the equity principle, leads us to the establishment of risk criteria. Newborn and under-one-year-old children who fit risk criteria should have special assistance assured. Objective: To demonstrate a new technological device, developed with the aim enrolling and following-up children who fit risk criteria. Method: A descriptive and retrospective analysis was developed with children born during the January $1^{\text {st }}$ and June $30^{\text {th }}$ period, at Diadema's Municipal Hospital, Diadema's State Hospital, at a private maternity ward located at the city, and public and private maternity wards located at nearby cities. Under-one-year-old children discharged from Diadema's Municipal Hospital, Diadema's State Hospital and Central Emergency Unit pediatric wards during the same period of time were also included in the research. Analyses of reports provided by the computerized system we also made. Results and Discussion: 636 children were enrolled in the project during the considered period, with a higher percentage of males. For children discharged from nursery wards, the main registration causes were Underweight or prematurity and Hyperbilirubinemia. For children discharged from pediatric wards, respiratory pathologies were paramount. These children's follow-up was not satisfactory. Conclusion: Although the software is an important device, allowing the registration and follow-up of children under risk factors, this new technological tool needs to be monitored. Furthermore, the information it provides should be applied for better software management.
\end{abstract}

Keywords: Newborn, Child, Infant Mortality, Risk, Computerized System, Internet. 


\section{ÍNDICE}

1. INTRODUÇÃO

2. OBJETIVOS 23

3. MÉTODO 24

3.1 CARACTERIZAÇÃO DO ESTUDO 24

3.2 CARACTERIZAÇÃO DA POPULAÇÃO DO ESTUDO 25

3.3 CARACTERIZAÇÃO DO LOCAL DA PESQUISA 29

3.3.1 Sistema de Saúde da Secretaria Municipal de Diadema 29

3.4 CARACTERIZAÇÃO DO PERÍODO DO ESTUDO 32

3.5 VARIÁVEIS DA PESQUISA 33

3.5.1 Relativas ao Uso do Sistema Informatizado 33

3.5.2 Relativas às Características das Crianças Incluídas no Projeto 33

3.6 PROCEDIMENTO PARA COLETA DE DADOS 34

3.7 ANÁLISE DOS DADOS 35

3.8 ASPECTOS ÉTICOS DA PESQUISA 36

4. RESULTADOS E DISCUSSÃO 37

4.1. UTILIZAÇÃO DO SISTEMA INFORMATIZADO 38

4.2. RELATIVAS ȦS CARACTERÍSTICAS DAS CRIANÇAS INSCRITAS

4.3. RELATIVAS AO ACOMPANHAMENTO DESTAS CRIANÇAS

4.4 RELATIVAS ÀS ALTAS DAS CRIANÇAS INSCRITAS 60

5. CONCLUSÃO 61

6. CONSIDERAÇÕES FINAIS

7. REFERÊNCIAS

ANEXOS

Anexo 1 - Parecer do Comitê de Ética em Pesquisa da Faculdade de Saúde Pública da USP (COEP/FSP). 69

Anexo 2 - Declaração de Anuência e Termo de Compromisso da Secretaria da Saúde do Município de Diadema. $\quad 70$

Anexo 3 - Telas do sistema informatizado 71

\section{CURRÍCULO LATTES}




\section{LISTA DE TABELAS E GRÁFICOS}

Tabela 1 - Distribuição do número e percentagem de recém-nascidos inscritos no projeto Criança de Risco, segundo local de inscrição, Diadema- São Paulo, 2010.

Tabela 2 - Distribuição no número de internações para o procedimento de parto, em residentes em Diadema- São Paulo, 2010.

Tabela 3 - Distribuição do número e percentagem de crianças inscritas no projeto Crianças de Risco, menores de um ano, pós-alta hospitalar, segundo local de inscrição, Diadema- São Paulo, 2010.

Tabela 4 - Distribuição das internações em Pediatria, ocorridas em residentes em Diadema - São Paulo, por serviços, de $1 .^{\circ} \mathrm{de}$ janeiro a 30 de junho de 2010.

Tabela 5 - Distribuição do número de recém-nascidos inscritos no projeto Crianças de Risco, por causas de inclusão e sexo, Diadema- São Paulo, 2010.

Tabela 6 - Distribuição do número de recém-nascidos inscritos no projeto Crianças de Risco, por causas de inclusão isoladas e sexo, Diadema - São Paulo, 2010.

Tabela 7 - Distribuição do número e percentagem dos recém-nascidos inscritos segundo peso de nascimento, Diadema- São Paulo, 2010.

Tabela 8 - Distribuição do número e percentagem dos recém-nascidos inscritos segundo comprimento ao nascimento, DiademaSão Paulo, 2010.

Tabela 9 - Distribuição do número e percentagem dos recém-nascidos inscritos segundo a idade gestacional materna, Diadema São Paulo, 2010. 
Tabela 10 - Distribuição do número e percentagem de recém-nascidos inscritos com idade gestacional referida igual ou superior a 37 semanas, segundo peso, Diadema - São Paulo, 2010.

Tabela 11 - Distribuição do número de crianças inscritas na condição de "pós-alta" hospitalar, segundo sexo, Diadema- São Paulo, 2010.

Tabela 12 - Distribuição das internações de crianças menores de um ano de idade, residentes em Diadema, segundo sexo, de 2005 a 2008.

Tabela 13 - Distribuição das internações de crianças menores de um ano de idade, segundo sexo, em residentes em DiademaSão Paulo, 2010.

Tabela 14 - Distribuição do número de internações em menores de um ano de idade, ocorridas no Brasil no período de 2008, 2009 e de janeiro a junho de 2010 , segundo sexo.

Tabela 15 - Distribuição do número e percentagem das causas de internação das crianças inscritas na condição "pós-alta" hospitalar, Diadema- São Paulo, 2010.

Tabela 16 - Distribuição do número e percentagem de crianças segundo o número de acompanhamentos realizados. Diadema- São Paulo, 2010.

Tabela 17 - Modelo matemático simplificado para avaliação das consultas de acompanhamento.

Tabela 18 - Percentagem de crianças segundo o número de acompanhamentos realizados e sexo. Diadema- São Paulo, 2010 .

Tabela 19 - Distribuição do número e percentagem de crianças que 60 tiveram alta do projeto segundo motivos. Diadema- São 
Paulo, 2010.

Gráfico 1 - Distribuição do número de recém-nascidos por comprimento ao nascer, segundo Idade Gestacional. Diadema- São Paulo, 2010.

Gráfico 2 - Avaliação da variação da Taxa de Mortalidade Infantil, por sexo, em Diadema, nos anos de 2000 a 2008, com linha de tendência. 


\section{Siglas Utilizadas}

$\begin{array}{lll}\text { BCP } & - & \text { Broncopneumonia } \\ \text { BE } & - & \text { Broncoespasmo } \\ \text { DDA } & - & \text { Doença Diarréia Aguda } \\ \text { IVAS } & - & \text { Infecção das Vias Aéreas Superiores } \\ \text { IRA } & - & \text { Insuficiência Renal Aguda } \\ \text { ITU } & - & \text { Infecção do Trato Urinário } \\ \text { RGE } & - & \text { Refluxo Gastro Esofágico } \\ \text { SEPSE } & - & \text { Septicemia } \\ \text { TCE } & - & \text { Traumatismo Crânio Encefálico }\end{array}$




\section{INTRODUÇÃO}

Nas últimas décadas do século XX, verificou-se um decréscimo na mortalidade infantil em todos os países. O que se observou, no entanto, é que enquanto nos países desenvolvidos essa queda se deu de maneira acelerada, nos de baixo e médio nível de desenvolvimento, ela ocorreu de maneira mais lenta e irregular (BHUTTA et al.,2005).

Essas quedas são atribuíveis a diversos fatores, sendo os mais importantes as melhorias das condições sócio-econômicas, o investimento e as políticas governamentais em saúde, os quais estimularam práticas de promoção e atenção à saúde (BUSS, 2000).

Dentre as características sócio-econômicas de uma sociedade, vale citar as condições de saneamento, nutrição, educação, habitação, condições de trabalho e lazer. E dentre as políticas de saúde, temos como ações prioritárias a assistência ao pré-natal, ao parto e puerpério, ao recém-nascido, aos programas de imunização e de puericultura (LAURENTI et al, 1975).

A Suécia tem apresentado o menor índice de mortalidade infantil desde a década de 20 do século passado, e nos anos 80, a Finlândia passou apresentar melhores indices de sobrevida (WALLACE et al., 1985). Em 1998, na Federação Russa, a mortalidade infantil foi de 18 por mil nascidos vivos, enquanto que no Japão essa taxa foi de quatro por mil nascidos vivos (OMS, 1999).

Vale aqui citar o ocorrido no Chile e em Cuba, que apesar de serem países em desenvolvimento, apresentaram declínio da mortalidade infantil de maneira expressiva. Em 1991, tal taxa era, em Cuba, 10,7 por mil nascidos vivos e, no Chile, 
14,6 por mil nascidos vivos. Em 2001, passou aos valores de 6,2 por mil nascidos vivos e 8,3 por mil nascidos vivos, respectivamente (DONOSO et al, 2004).

A promulgação da nova Constituição Federal em 1988 (Constituição da República Federativa do Brasil, 1988), veio colaborar com a queda da mortalidade infantil no país como um todo, pois antes desta, o acesso à saúde da população brasileira se fazia de maneira disforme, privilegiando certas camadas, como a dos empregados com carteira assinada e a dos que dispunham de recursos financeiros, em detrimento dos mais necessitados. O fato de se escrever na carta magna que Saúde é direito de todos e dever do Estado teve um grande impacto na formação de uma nova maneira de organização dos serviços, com a criação do Sistema Único de Saúde (SUS). Porém as repercussões dessa mudança se deram de maneira lenta e gradual. (ABREU et al, 2007).

No ano de 1978, a Reunião de Alma-Ata colaborou para inspirar esse rearranjo da assistência à saúde brasileira, quando a Organização Mundial da Saúde (OMS) convocou, em colaboração com o Fundo das Nações Unidas para a Infância (UNICEF), a I Conferência Internacional sobre Cuidados Primários de Saúde. A conferência trouxe um novo enfoque para o campo da saúde, colocando a meta de "saúde para todos no ano 2000 " e recomendando a adoção de um conjunto de oito elementos essenciais: educação dirigida aos problemas de saúde prevalentes e métodos para sua prevenção e controle; promoção do suprimento de alimentos e nutrição adequada; abastecimento de água e saneamento básico apropriados; atenção materno-infantil, incluindo o planejamento familiar; imunização contra as principais doenças infecciosas; prevenção e controle de doenças endêmicas; tratamento 
apropriado de doenças comuns e acidentes; e distribuição de medicamentos básicos (BUSS, 2000).

No Brasil, há uma tendência de queda da mortalidade infantil desde a década de 30 do século passado. Em 1930, a taxa que era estimada em 168 por mil nascidos vivos, se mantém nesses patamares até a década de 60 (IBGE, 1999). No final do século $\mathrm{XX}$, temos uma queda acentuada, indo de 33,2 por mil nascidos vivos na década de 90 para 24,4 em 2003 (MINISTÉRIO DA SAÚDE, 2005). Apesar da importância desses valores, temos a constatação das grandes diferenças que encontramos em nosso país, conforme a região avaliada (SIMÕES et al., 1995).

Mesmo com a constatação de que a maioria dos indicadores de saúde no Brasil mostra progressos (tais como a mortalidade infantil; déficits de altura entre crianças menores de 5 anos, que diminuíram de $37 \%$, em 1974-75, para 7\%, em 2006-07; duração mediana da amamentação, que aumentou de 2,5 meses nos anos 1970 para 14 meses em 2006-07), um demonstra piora, que é o da prevalência dos partos prematuros (VICTORA et al., 2011). Através de uma revisão sistemática de estudos de base populacional de nascimentos pré-termo, observou-se que a prevalência destes aumentou de cerca de $4 \%$, no início dos anos 1980 , para mais de $10 \%$, após o ano 2000. Essa tendência de aumento foi confirmada por estudos periódicos realizados em duas cidades brasileiras, Ribeirão Preto-SP e Pelotas-RS, utilizando-se métodos padronizados ao longo do tempo (BARROS et al., 2005) (BETTIOL et al.,2000).

A prematuridade, definida como idade gestacional inferior a 37 semanas, é a principal causa de mortes infantis no Brasil, e seu aumento tem anulado os avanços conseguidos na sobrevida de recém-nascidos de baixo peso, aqueles com peso 
inferior a $2.500 \mathrm{~g}$, por conta das melhorias na atenção neonatal. A contribuição das intervenções médicas, como as cesarianas, para o aumento dos nascimentos prétermo tem sido bastante discutida no Brasil: enquanto alguns estudos mostram uma associação (SILVA et al., 2004), outros indicam que o nascimento pré-termo aumentou igualmente entre os nascimentos por cesariana ou por parto vaginal (BARROS et al., 2008).

A maioria dos recém-nascidos pré-termo tem idade gestacional entre 34 e 36 semanas, com peso ao nascer superior a $2500 \mathrm{~g}$. Apesar do crescimento do número de nascimentos pré-termos, a prevalência de baixo peso ao nascer tem permanecido estável, no patamar de 8\%, desde o ano 2000 (DATASUS, 2006). Uma explicação possível para essa tendência de estabilidade do baixo peso ao nascer está na redução da frequência de retardo de crescimento intrauterino, (BARROS et al., 2008), equilibrando o efeito negativo do aumento da prematuridade.

No estado de São Paulo, tivemos um declínio histórico da mortalidade infantil de 115 por mil nascidos vivos em 1950 (LAURENTI, 1987) para 15,2 por mil nascidos vivos em 2003 (MS, 2005). No micropolo da Região metropolitana de São Paulo, observou-se uma taxa de mortalidade infantil semelhante à de São Paulo capital. Na cidade de Diadema, de acordo com REIS (2000), o coeficiente de mortalidade era de 209,8 por mil nascidos vivos em $1970,82,9$ em 1980 , de 36,0 em 1990, e 21,20 em 1997. Dados mais recentes do DataSus (DATASUS, 2010), situam a mortalidade infantil em Diadema em 14,7 por mil nascidos vivos em 2007. 
A melhoria dos serviços de saúde, com a agregação de maior tecnologia, resultou em aumento dos custos de forma exponencial, enquanto que os recursos disponiveis se apresentam sempre insuficientes para fazer frente às demandas.

Visando uma melhor utilização das dotações da saúde e o atendimento do princípio da equidade, que trata de uma distribuição dos recursos disponíveis através de uma discriminação positiva em favor dos mais desfavorecidos, tornou-se evidente a necessidade de se trabalhar com grupos de risco, e para isso, definir-se o que é risco à saúde. A avaliação de risco busca a prevenção de doença, ou quando esta já se encontra instalada, do aparecimento de sequelas ou do óbito (DUARTE, 2000).

Essa seria uma forma de direcionar melhor os recursos finitos, privilegiando a busca e o acompanhamento dos mais desfavorecidos ou dos que necessitam de cuidados diferenciados.

Fazem parte destes grupos os recém-nascidos, os desnutridos, as gestantes, os idosos, pacientes portadores de doenças crônicas, assim como os portadores de graves patologias.

Para se trabalhar com os recém-nascidos e se avaliar os riscos dessa faixa etária, RUMEL e CAPISTRANO (1992) pesquisaram os atestados de óbito e definiram quais as patologias e fatores associados eram mais frequentemente encontrados. Esse trabalho foi realizado na Secretaria de Higiene e Saúde do município de Bauru, interior do estado de São Paulo.

Os autores estabeleceram então alguns critérios para a seleção de crianças de risco. Trabalhou-se com a idéia de Indicadores de maior risco, definidos como:

- peso ao nascer inferior a $2.500 \mathrm{~g}$, 
- prematuridade,

- gravidez manifestadamente indesejada, e

- malformação congênita

E igualmente, trabalhou-se com Indicadores de menor risco, que ainda atestam tal condição, mas com menor severidade. São eles:

- renda familiar per capita mensal igual ou menor que $1 / 4$ do salário mínimo

- mãe sem companheiro

- recém-nascido com 2 ou mais irmãos menores de 4 anos

- mãe analfabeta

- mãe com menos de 3 consultas de pré-natal na gravidez

- desemprego do chefe da família

- idade materna inferior a 18 anos

Essa ação de definir grupos de risco entre os recém-nascidos, associada a um conjunto de medidas de atenção diferenciada a essas crianças, tais como visita domiciliar, garantia de consulta médica e de enfermagem em intervalos mais curtos, propiciou uma redução da mortalidade infantil notada em curto período de tempo na cidade analisada na pesquisa.

Muitos municípios copiaram essa estratégia, dentre eles Diadema, que buscava reduzir suas taxas de mortalidade infantil, então muito elevadas.

Criou-se assim o "Projeto Nascer" no ano de 2000, que também utilizava a lógica de critérios de risco para definir a inclusão dos recém-nascidos. Utilizava-se ficha de inscrição que era preenchida na Maternidade, ou na Unidade Básica de Saúde (UBS) para crianças nascidas fora do município; e também planilha de 
acompanhamento na UBS. Todo esse material era encaminhado para digitação na Coordenação da Atenção Básica do município. As crianças que eram inscritas nesse projeto tinham garantia de atendimento prioritário na UBS, visto que a Maternidade agendava, através de contato telefônico e antes mesmo da alta do recém-nascido, consulta com pediatra.

Dadas as mudanças ocorridas na Atenção Básica em Diadema, com a opção pela Estratégia de Saúde da Família e Estratégia de Agentes Comunitários de Saúde para cobertura de grande parcela da população; dada a dificuldade no agendamento por telefone que as Maternidades referiam; e com a inoperabilidade no gerenciamento do Projeto Nascer, devido à falta de profissionais para digitar tantas fichas, optou-se por uma mudança que trouxesse maior agilidade e facilitasse o controle gerencial desse Projeto.

Buscando a elaboração de um novo sistema que facilitasse o cadastro e o acompanhamento dessas crianças de risco, criou-se na Internet o sistema informatizado "Crianças de Risco"!

Os critérios de risco foram definidos em reuniões realizadas com os neonatologistas, pediatras, médicos generalistas e enfermeiros da Rede de Saúde de Diadema, buscando-se uma interface entre os dados da literatura, as situações observadas no cotidiano dos atendimentos e a dinâmica que as situações de risco

1 PEREZ, Edson A., Elaboração de um sistema informatizado para cadastro e acompanhamento de recém-nascidos de risco. Artigo aceito para publicação pela Revista Brasileira de Crescimento e Desenvolvimento Humano. 
impõem aos serviços de saúde. O mesmo valeu para os critérios de saída das crianças deste projeto.

Os hospitais Municipal e Estadual de Diadema, assim como o Pronto Socorro Central de Diadema, cadastram as crianças, no momento de suas altas, no sistema informatizado.

A Unidade Básica de Saúde acessa a Internet com a periodicidade de duas a três vezes por semana, ou mais vezes, caso julgue necessário, e imprime relatório em que constam os nomes das mães e endereços das crianças inscritas, no período desejado. Define, a seguir, um cronograma de visitas domiciliares com os seus profissionais de saúde, dentro da lógica da Estratégia da Saúde da Família, buscando assim uma avaliação rápida da situação de risco e intervindo da maneira em que a equipe julgue necessária (agendamento de consulta, encaminhamentos, novas visitas domiciliares). A Unidade Básica de Saúde também tem o compromisso de digitar estes acompanhamentos e de cadastrar no sistema informatizado os recém-nascidos provenientes do único hospital privado de Diadema e das demais maternidades públicas ou privadas de outros municípios, assim como as crianças menores de 1 ano e que tiveram alta do hospital privado de Diadema ou de hospitais de outros municípios.

Cabe aqui lembrar que concomitante à criação deste projeto, decidiu-se pela criação de um Ambulatório Especializado em crianças prematuras ou de baixo peso, buscando agilizar o atendimento destes frente às suas peculiaridades e estabelecendo o sistema de inter-consultas com os demais especialistas (cardiologistas, oftalmologistas, ortopedistas). Este Ambulatório Especializado passou a ocupar um 
espaço no Quarteirão da Saúde, local onde se encontram os serviços de especialidades e o Pronto Socorro Central do município de Diadema.

Houve consenso de que as crianças prematuras e as de baixo peso deveriam ser acompanhadas também em suas Unidades Básicas de Saúde, devendo obedecer a uma agenda mínima de consulta quinzenal, uma no Ambulatório Especializado e a outra com médico pediatra ou generalista em sua Unidade Básica de Saúde, visto a importância da manutenção de vínculo com o serviço mais próximo e a possibilidade que a Estratégia de Saúde da Família dá de maior conhecimento das realidades de vida a que estas crianças estão submetidas.

Justifica-se a realização deste estudo para que as informações aqui geradas possam contribuir para o aprimoramento das políticas assistenciais do município de Diadema, assim como fornecer subsídios para outros municípios que tenham interesse nessa proposta, que visa principalmente à queda da mortalidade infantil com a melhoria da qualidade de vida de nossas crianças. 


\section{OBJETIVOS}

2.1. Geral: demonstrar a utilização de uma nova ferramenta tecnológica desenvolvida com o intuito de cadastrar e acompanhar crianças de risco.

\subsection{Específicos:}

- Descrever a utilização do sistema informatizado "Projeto Crianças de Risco" no município de Diadema.

- Descrever os critérios de inclusão e de alta no Projeto Crianças de Risco

- Avaliar as características das crianças incluídas nesse Projeto.

- Subsidiar uma estimativa da cobertura das crianças de risco no município. 


\section{MÉTODO}

\subsection{CARACTERIZAÇÃO DO ESTUDO}

Foi realizado um estudo do tipo descritivo, retrospectivo, com crianças nascidas no Hospital Municipal de Diadema, Hospital Estadual de Diadema, em uma maternidade privada do município (Hospital São Lucas), ou em outras maternidades públicas e privadas de outros municípios, filhos de mães residentes em Diadema. Também fizeram parte desse estudo crianças menores de um ano, residentes em Diadema, egressas das enfermarias de pediatria do Hospital Municipal de Diadema, Hospital Estadual de Diadema, do Pronto Socorro Central e de hospitais de outros municípios.

O período de avaliação do sistema informatizado e de suas informações se estendeu de $1 .^{\circ}$ de janeiro a 30 de junho de 2010. 


\subsection{CARACTERIZAÇÃO DA POPULAÇÃO DE ESTUDO}

A população de crianças avaliada neste estudo correspondeu a 636 crianças, sendo 437 provenientes dos berçários (recém-nascidos) e 219 provenientes de alta hospitalar e menores de um ano de idade, sendo destas, duas altas por patologias cirúrgicas. Vale lembrar que o número maior de inscritos em relação ao de participantes, 656 crianças, se deveu à reinscrição que diferentes profissionais que utilizaram o sistema informatizado realizaram, apesar da orientação de verificação prévia da existência do cadastro da criança no sistema antes da realização de uma nova inscrição.

Constatou-se, no período analisado, que este erro ocorreu por dezoito vezes e nas situações: nove crianças que saíram do Berçário, já incluídas no Projeto, foram reinternadas e reinscritas, e uma delas por duas vezes. Das crianças inscritas pelo motivo "pós-alta hospitalar", tivemos que sete delas foram reinternadas por mais uma vez e reinscritas, e uma criança por mais duas vezes. O correto e o que foi orientado era a introdução de qualquer nova ocorrência como acompanhamento. Há também a possibilidade de reinscrição de uma criança que já teve alta do projeto, desde que ela ainda não tenha um ano de idade e venha a ser exposta a uma nova situação de risco. Tivemos a ocorrência deste fato para duas crianças, sendo que estes casos não se constituíram em erro, visto que esta é uma situação já prevista pelo sistema informatizado.

Quanto ao sexo, observamos que 253 eram do sexo feminino e 383 , do masculino. Tivemos a ocorrência, no período analisado, de oito partos gemelares e de dois trigemelares. 
Todas as crianças inscritas eram filhos de mães residentes na cidade de Diadema, e nascidas no Hospital Municipal de Diadema, Hospital Estadual Diadema, Hospital São Lucas - um hospital privado localizado no município de Diadema e que atende gestantes particulares e as vinculadas a convênios médicos-, e em outros hospitais localizados em outros municípios da região, fossem públicos ou privados. No caso de nascimento em outros hospitais, quem realizou a inscrição foi a Unidade Básica de Saúde ao qual a criança foi vinculada.

Dentre as crianças nascidas nas Maternidades citadas, foram incluidas aquelas que apresentaram um ou mais fatores de risco pré-definidos pelos profissionais de saúde envolvidos no projeto, e que são citados a seguir: baixo peso ou prematuridade, hiperbilirrubinemia, escore de Apgar do $5 .^{\circ}$ minuto menor do que 7 , hipoglicemia neonatal, infecção congênita, malformação congênita, mãe dependente química, gravidez manifestadamente indesejada, mãe com distúrbio psiquiátrico, mãe adolescente e com ausência de vínculo mãe filho, história de violência familiar, e recém nascido com história ou suspeita de negligência durante sua internação no berçário. Todas as crianças que tiveram alta hospitalar, menores de um ano de idade, foram consideradas de risco, independente da patologia que as levou à internação.

Para a manutenção das crianças no projeto, fez-se necessário o acompanhamento destas nas Unidades Básicas de Saúde do municipio de Diadema e no Ambulatório de Prematuros para as de baixo peso ou prematuras.

Toda criança inscrita recebeu visita domiciliar por parte da equipe de saúde (agentes comunitários de saúde, enfermagem e médicos), e teve seu agendamento de consulta garantido, fosse com pediatra, médico generalista ou com o neonatologista do Ambulatório de Prematuros. Para alguns casos optou-se também por um intervalo 
entre as consultas menor que o utilizado pelo Sistema de Saúde em Diadema (consultas de puericultura mensais até os 6 meses de idade e bimestrais dos 8 aos 12 meses).

Para a identificação da criança, foram utilizados no sistema os campos:

-Data da inscrição

-UBS em que a mãe ou a criança está matriculada

-Número da matrícula da mãe

-Endereço

-Bairro

-Telefone

-Matrícula da criança

-Nome da criança

-Data do nascimento

-Local do Nascimento (com as opções: Hospital Municipal de Diadema, Hospital Estadual de Diadema, Hospital São Lucas e Outros)

-Sexo (Masculino, Feminino e Indefinido)

Para a caracterização do recém-nascido:

-Peso $(\mathrm{g})$

-Comprimento $(\mathrm{cm})$

-Perímetro Cefálico

-Idade Gestacional materna

-Apgar $1 .^{\circ} \min$

-Apgar $5 .^{\circ} \mathrm{min}$

-Capurro 
Para os motivos de inclusão, foram oferecidas as opções (com a possibilidade de mais de uma ser anotada):

-Baixo Peso ou Prematuridade

-Hiperbilirrubinemia

-Apgar $5 .^{\circ} \min <7$

-Hipoglicemia neonatal

-Infecção Congênita

-Malformação Congênita

-Mãe Dependente Química

-Gravidez manifestadamente indesejada

-Mãe com distúrbio psiquiátrico

-Mãe adolescente e ausência de vínculo mãe filho

-Violência

-RN com história ou suspeita de negligência

-Criança pós-alta menor de 1 ano de idade (alta clínica, alta cirúrgica, vítima de violência ou negligência)

-Observações necessárias

Para o Acompanhamento das crianças, temos os campos (não obrigatórios):

-Peso $(g)$

-Comprimento $(\mathrm{cm})$

-Persiste a causa da matrícula (sim ou não)

-Motivo da alta (com as opções: Bom ganho de peso, Maior de um ano de idade, Mudança de município, Óbito, Situação de risco afastada e Outros) 


\subsection{CARACTERIZAÇÃO DO LOCAL DE PESQUISA}

Diadema é um município do Estado de São Paulo, na mesorregião Metropolitana de São Paulo e microrregião de São Paulo.

Dista da capital do Estado 19 quilômetros e ocupa uma área de $31 \mathrm{~km}^{2}$. A população recenseada pelo IBGE no ano de 2000 foi de 357.064 habitantes (IBGE, 2010). Em 2010, preliminares do censo populacional dadas por este Instituto era de 386.039 habitantes, o que correspondia a uma densidade demográfica de $12.452,8$ $\mathrm{hab} / \mathrm{km}$.

\subsubsection{Sistema de Saúde da Secretaria Municipal de Diadema}

Em 1983, Diadema contava com apenas um pronto-socorro e oito postos de puericultura para onze bairros. A partir da luta constante dos Conselhos Populares de Saúde e da vontade política da Administração Municipal, conseguiu-se implantar uma Rede Municipal de Saúde.

Atualmente, o Sistema de Saúde de Diadema está organizado nos níveis de atenção (GOMES et al.,2008):

1- Atenção Básica: composta por 20 Unidades Básicas de Saúde, que contam com recepção, consultórios médicos, odontológicos e de enfermagem, farmácia, salas de curativos, de coleta de materiais, de imunização e de grupos educativos. A Estratégia de Saúde da Família tem uma cobertura atual de $70 \%$ do município, atuando com equipes compostas por médicos, dentistas, enfermeiros, 
técnicos de enfermagem, e auxiliares de consultório dentário ou técnicos em higiene dental.

2- $\quad$ Atenção Especializada: composta de um Centro de Especialidades Médicas e Exames Diagnósticos, localizados no Quarteirão da Saúde. Atuam como referência e contra-referência para aqueles casos que exigem a ação de um especialista ou de exames subsidiários para a definição de diagnóstico e adequada instituição de terapêutica. São atendidas 26 diferentes especialidades distintas, somando-se a estas a de neonatologia para crianças de baixo peso ou prematuros. Conta ainda com centro de diagnósticos por imagem, endoscopia, especialidades odontológicas, reabilitação, laboratório de análises clínicas e um centro cirúrgico ambulatorial.

3- $\quad$ Rede de Atenção à Saúde Mental: Prevê atenção integral aos pacientes com transtornos mentais e dependência química. Além do tratamento clínico, desenvolve oficinas terapêuticas e culturais incentivando a geração de renda e o retorno ao convívio social. $\mathrm{O}$ atendimento é oferecido por 5 Centros de Atenção Psicossocial (CAPS): Centro Norte, Leste, Sul e Espaço Fernando Ramos (CAPSÁlcool e Droga), CAPS Infantil, Unidades Básicas de Saúde, Emergência Psiquiátrica e Ambulatório de Psiquiatria.

4- $\quad$ Assistência Farmacêutica: garante a distribuição dos medicamentos essenciais e a sua utilização racional. A dispensação é realizada em todas as Unidades Básicas de Saúde, no Centro de Referência e Tratamento (CRT) em Doenças Sexualmente Transmissíveis e Hepatites, e nos CAPSs. O município também dispõe de duas unidades da Farmácia Popular, programa do Ministério da Saúde. 
5- Vigilância à Saúde: que conta com os equipamentos: Centro de Referência e Tratamento (CRT) em Doenças Sexualmente Transmissiveis e Hepatites, Centro de Referência em Saúde do Trabalhador, Centro de Controle de Zoonoses, Vigilância Epidemiológica, Vigilância Sanitária e Vigilância Ambiental. A Vigilância à Saúde atua principalmente na detecção e prevenção de doenças através da análise das informações fornecidas por todos os tipos de atividades realizadas no município, sejam elas provenientes da área da saúde, comércio, produção de bens, educação,...

6- $\quad$ Serviços 24 horas (Urgência e Emergência): conta com 3 serviços de Pronto Atendimento: o PA Eldorado, o PA Paineiras, e o PA Pediátrico Jardim das Nações; e mais o Pronto-Socorro Central, localizado no Quarteirão da Saúde, com atendimento pediátrico, de clínica médica e ortopédico; e o Pronto Socorro do Hospital Municipal de Diadema, com atendimento de clínica médica, ginecoobstetrícia e ortopédico.

7- Serviço Hospitalar: conta com o Hospital Municipal de Diadema, o Hospital Estadual Serraria, ambos públicos, e um hospital particular, o Hospital São Lucas. Estes três hospitais gerais contam com Maternidades, berçários e enfermarias de pediatria. Vale ressaltar que o Pronto-Socorro Central também realiza internações de crianças, sendo portanto, considerado unidade hospitalar. 


\subsection{CARACTERIZAÇÃO DO PERÍODO DO ESTUDO}

Optou-se pela definição do periodo de $1 .^{\circ}$ de janeiro a 30 de junho, visando a diminuir o viés de se realizar este estudo em meses de maior ou menor prevalência de algumas doenças sazonais.

Cabe ressaltar que crianças que já se encontravam matriculadas no projeto antes deste período não foram avaliadas, o mesmo ocorrendo com as altas que se deram para as crianças avaliadas, mas que ocorreram em datas posteriores a 30 de junho de 2010. 


\subsection{VARIÁVEIS DA PESQUISA}

\subsubsection{Relativas ao Uso do Sistema Informatizado}

- Número de crianças matriculadas no período de $1 .^{\circ}$ de janeiro a 30 de junho de 2010;

- Número de consultas de seguimento realizadas neste período;

- Número de altas das crianças inscritas neste período.

\subsubsection{Relativas às Características das Crianças Incluídas no Projeto}

- Motivos de inclusão - avaliar as porcentagens dos critérios que levaram essas crianças a fazerem parte deste projeto.

- $\quad$ Peso e comprimento dos recém-nascidos - avaliar este dado comparando-o com a idade gestacional materna

- Sexo das crianças inscritas no projeto.

- Motivos de alta e períodos entre a inclusão da criança e a saída do projeto. 


\subsection{PROCEDIMENTOS PARA COLETA DE DADOS}

A coleta de dados se deu através da obtenção dos relatórios que o sistema informatizado disponibiliza. A partir da opção por Relatórios, são fornecidos os tipos:

-Relatório gerencial

-Relatório de matrículas

-Relatório analítico por paciente

-Relatório de alta

-Relatório de acompanhamentos

Definido o período desejado, obtivemos uma planilha que pode ser exportada no formato Excel, e assim ser salva com o nome desejado. 


\subsection{ANÁLISE DE DADOS}

Através da utilização do programa Epi Info, software disponibilizado pelo CDC - Centers for Disease Control, foram feitas as análises das planilhas obtidas pelo sistema informatizado que o projeto Crianças de Risco utiliza.

Trata-se de uma análise descritiva a partir de informações sobre frequências, proporções, média e mediana, resultante da consolidação dos dados constantes das planilhas.

As informações finais obtidas foram organizadas nas formas de tabelas e gráficos. 


\subsection{ASPECTOS ÉTICOS DA PESQUISA}

A pesquisa foi realizada segundo as normas que regulamentam a pesquisa em seres humanos, contidas nas resoluções n. ${ }^{\circ}$ s 196/96 e 251/97 do Conselho Nacional de Saúde, de acordo com o Comitê de Ética em Pesquisa da Faculdade de Saúde Pública da Universidade de São Paulo (Anexo 1).

A pesquisa dependeu da autorização dos Comitês de Ética Institucionais.

A Secretaria Municipal de Saúde de Diadema concordou com a utilização dos dados do sistema informatizado, estando em anexo a cópia da autorização (Anexo 2).

Vale salientar que na pesquisa não foram fornecidas informações que permitissem a identificação das crianças ou de seus pais, endereços, telefones e fontes dos cadastros. 


\section{RESULTADOS E DISCUSSÃO}

Foram avaliados os relatórios provenientes do sistema informatizado Projeto Crianças de Risco, extraídos pela Internet. Visou-se à caracterização das crianças inscritas no projeto segundo as variáveis: sexo, proveniência, motivo da inscrição, peso e comprimento (quando do nascimento), idade gestacional para os provenientes dos berçários, número de consultas de acompanhamento, tempo de permanência no projeto e motivos de altas. Esses resultados são demonstrados nas tabelas e gráficos a seguir.

De um total de 636 crianças participantes, obtivemos dados para todas as variáveis pesquisadas, com exceção para o motivo da inscrição "Pós-Alta Clínica", em que observamos a inexistência do dado em 13 casos, constando em nossa pesquisa como motivo "Ignorado". 


\subsection{UTILIZAÇÃO DO SISTEMA INFORMATIZADO}

Obtivemos um total de 656 inscrições no período estudado para um total de 636 crianças participantes. Esse fato se deveu aos erros na utilização do sistema, reinscrição de criança já cadastrada (dezoito ocorrências) e a reinscrição de duas crianças que já haviam recebido alta do Projeto, pelo motivo de alta e nova situação de risco ocorrida a posteriori.

Quanto ao sexo dos participantes, tivemos que 383 eram do sexo masculino e 253 ao feminino.

Em relação ao local de inscrição dos recém-nascidos, temos:

Tabela 1 - Distribuição do número e percentagem de recém-nascidos inscritos no projeto Criança de Risco, segundo local de inscrição, Diadema, $1 .^{\circ}$ de janeiro a 30 de junho de 2010.

\begin{tabular}{lcc}
\hline LOCAL DA INSCRIÇÃO & $\mathbf{N .}^{\circ}$ & $\%$ \\
\hline HOSP MUNICIPAL DE DIADEMA & 261 & $59,83 \%$ \\
HOSP ESTADUAL DE DIADEMA & 110 & $25,16 \%$ \\
OUTROS & 55 & $12,68 \%$ \\
HOSPITAL SÃO LUCAS & 11 & $2,33 \%$ \\
\hline TOTAL & $\mathbf{4 3 7}$ & $\mathbf{1 0 0 , 0 0 \%}$ \\
\hline
\end{tabular}


Tabela 2. Distribuição no número de internações para o procedimento de parto, em residentes em Diadema, por tipo de gestão, janeiro a junho de 2010. Fonte Ministério da Saúde - Sistema de Informações Hospitalares do SUS (SIH-SUS).

\begin{tabular}{lcc} 
Gestão & $\begin{array}{c}\mathbf{N}^{\circ} \text { de } \\
\text { partos }\end{array}$ & $\mathbf{\%}$ \\
\hline Federal & 16 & 0,86 \\
Estadual & 942 & 50,75 \\
Municipal & 799 & 43,05 \\
Outros & 99 & 5,33 \\
\hline Total & $\mathbf{1 8 5 6}$ & $\mathbf{1 0 0}$
\end{tabular}

Explicarmos a ocorrência de mais inscrições no Hospital Municipal em relação ao Hospital Estadual, analisando conjuntamente a tabela 1 e 2.

Verificamos assim que o número de partos realizados no período do estudo não explica o fato de ser o Hospital Municipal o que mais inscreveu recém-nascidos no projeto. A justificativa seria que este hospital é do tipo porta aberta, ou seja, dispõe de um pronto-socorro que acolhe a todas as gestantes que procuram aquele serviço. O mesmo não ocorre com o Hospital Estadual, que não dispõe de serviço de prontosocorro e interna apenas pacientes pré selecionadas.

As crianças em situação de risco que foram inscritas utilizaram todas as opções inicialmente previstas, com exceção de "Gravidez manifestadamente indesejada", a qual não foi a motivadora da inscrição de nenhuma das crianças analisadas. Isto talvez se deva ao fato de que tal situação realmente não tenha ocorrido, ou porque o tempo para a avaliação da relação mãe-filho na maternidade fosse pequeno, o que não possibilitou tal diagnóstico. 
Em relação ao local de inscrição das crianças pós-alta hospitalar, temos:

Tabela 3 - Distribuição do número e percentagem de crianças inscritas no projeto Crianças de Risco, menores de um ano, pós-alta hospitalar, segundo local de inscrição, Diadema, $1 .^{\circ}$ de janeiro a 30 de junho de 2010.

\begin{tabular}{lcc}
\hline LOCAL DA INSCRIÇÃO & $\mathbf{N}^{{ }^{\circ}}$ & $\%$ \\
\hline HOSP ESTADUAL DE DIADEMA & 102 & $46,76 \%$ \\
PRONTO SOCORRO CENTRAL & 58 & $26,86 \%$ \\
HOSP MUNICIPAL DE DIADEMA & 54 & $24,87 \%$ \\
OUTROS & 5 & $2,48 \%$ \\
\hline TOTAL & 219 & $100,00 \%$ \\
\hline
\end{tabular}

Tabela 4. Distribuição das internações em Pediatria, ocorridas em residentes em Diadema, por serviços, de $1 .^{\circ}$ de janeiro a 30 de junho de 2010 . Fonte: Ministério da Saúde. Sistema de Informações Hospitalares do SUS (SIH/SUS).

\begin{tabular}{lcc} 
Serviços & $\begin{array}{c}\text { N. }{ }^{\circ} \text { de } \\
\text { internaçōes }\end{array}$ & $\%$ \\
\hline $\begin{array}{l}\text { Hospital Estadual de Diadema } \\
\text { Hospital Municipal de Diadema e Pronto Socorro }\end{array}$ & 1113 & 44,43 \\
Central Municipal & 1392 & 55,57 \\
\hline Total & 2505 & 100,00
\end{tabular}


Apesar de o Sistema de Informações Hospitalares não disponibilizar faixas etárias na opção Pediatria por tipo de Serviço, analisando conjuntamente as duas tabelas, observamos que as porcentagens estão muito próximas às verificadas para as crianças menores de um ano de idade e que foram inscritas. 


\subsection{RELATIVAS ÀS CARACTERÍSTICAS DAS CRIANÇAS INSCRITAS}

Do ponto de vista das características dos recém-nascidos, procuramos nos ater aos motivos das inscrições destes no projeto, associados ao sexo (tabela 5), às causas referidas isoladas, e associadas ao sexo (tabela 6), ao peso ao nascimento (tabela 7), ao comprimento ao nascimento (tabela 8) e à idade gestacional materna (tabela 9).

Apresentam-se as duas tabelas em relação à causa da inclusão pelo fato de que muito freqüentemente temos a existência de mais de um motivo para a inclusão do mesmo recém-nascido.

Tabela 5. Distribuição do número de recém-nascidos inscritos no projeto Crianças de Risco, por causas da inclusâo e sexo, Diadema, $1 .^{\circ}$ de janeiro a 30 de junho de 2010.

\begin{tabular}{|c|c|c|c|}
\hline MOTIVO DA INCLUSÃO & FEM & MASC & TOTAL \\
\hline HIPERBILIRRUBINEMIA & 60 & 89 & 149 \\
\hline BAIXO PESO OU PREMATURIDADE & 45 & 65 & 110 \\
\hline BAIXO PESO OU PREMATURIDADE, HIPERBILIRRUBINEMIA & 20 & 34 & 54 \\
\hline INFECÇĀO CONGENITA & 13 & 11 & 24 \\
\hline MA FORMAÇĀO CONGENITA & 10 & 8 & 18 \\
\hline HIPERBILIRRUBINEMIA, MÁ FORMAÇĀO CONGENITA & 6 & 10 & 16 \\
\hline APGAR $5^{\circ}$ MIN $<7$ & 5 & 7 & 12 \\
\hline BAIXO PESO OU PREMATURIDADE, MÃE DEPENDENTE QUIMICA & 2 & 4 & 6 \\
\hline MĀE ADOLESCENTE E AUSÊNCIA DE VINCULO MÃE FILHO & 3 & 3 & 6 \\
\hline BAIXO PESO OU PREMATURIDADE, APGAR $5^{\circ}$ MN $<7$ & 2 & 2 & 4 \\
\hline BAIXO PESO OU PREMATURIDADE, MÁ FORMAÇÃO CONGENITA & 1 & 3 & 4 \\
\hline MÄE DEPENDENTE QUIMICA & 0 & 4 & 4 \\
\hline HIPERBILIRRUBINEMIA, INFECÇĀO CONGENITA & 1 & 2 & 3 \\
\hline HIPOGLICEMIA NEONATAL & 2 & 1 & 3 \\
\hline BAIXO PESO OU PREMATURIDADE, HIPERBILIRRUBINEMIA, MÁ FORMAÇĀO CONGENITA & 0 & 2 & 2 \\
\hline BAIXO PESO OU PREMATURIDADE, HIPOGLICEMIA NEONATAL & 2 & 0 & 2 \\
\hline BAIXO PESO OU PREMATURIDADE, INFECÇĀO CONGENITA & 2 & 0 & 2 \\
\hline BAIXO PESO OU PREMATURIDADE, MÃE ADOLESCENTE E AUSÊNCIA DE VINCULO MĀE FILHO & 2 & 0 & 2 \\
\hline BAIXO PESO OU PREMATURIDADE, MÃE DEPENDENTE QUIMICA, INFECÇĀO CONGENITA & 0 & 2 & 2 \\
\hline INFECÇÃO CONGENITA, MA FORMAÇĀO CONGENITA & 2 & 0 & 2 \\
\hline MÄE ADOLESCENTE E AUSÊNCIA DE VINCULO MĀE FILHO, MÁ FORMAÇĀO CONGENITA & 0 & 2 & 2 \\
\hline MÄE COM DISTURBIO PSIQUIÁTRICO & 1 & 1 & 2 \\
\hline BAIXO PESO OU PREMATURIDADE, HIPERBILIRRUBINEMIA, APGAR $5^{\circ} M I N<7$ & 1 & 0 & 1 \\
\hline BAIXO PESO OU PREMATURIDADE, HIPERBILIRRUBINEMIA, HIPOGLICEMIA NEONATAL. & 0 & 1 & 1 \\
\hline BAIXO PESO OU PREMATURIDADE, INFECÇĀO CONGENITA, MÁ FORMAÇĀO CONGENITA & 0 & 1 & 1 \\
\hline BAIXO PESO OU PREMATURIDADE, MÄE DEPENDENTE QUIMICA, HIPERBILIRRUBINEMIA & 0 & 1 & 1 \\
\hline HIPERBILIRRUBINEMIA, APGAR $5^{\circ}$ MIN $<7$ & 0 & 1 & 1 \\
\hline MĀE DEPENDENTE QUIMICA, INFECÇĀO CONGENITA, MÁ FORMAÇĀO CONGENITA & 0 & 1 & 1 \\
\hline MĀE DEPENDENTE QUIMICA, MĀE ADOLESCENTE E AUSÉNCIA DE VINCULO MAEE FILHO & 1 & 0 & 1 \\
\hline MĀE DEPENDENTE QUIMICA, MÁ FORMAÇÃO CONGENITA & 1 & 0 & 1 \\
\hline Total Bercário & 182 & 255 & 437 \\
\hline
\end{tabular}


Tabela 6. Distribuição do número de recém-nascidos inscritos no projeto Crianças de Risco, por causas de inclusão isoladas e sexo, Diadema, $1 .^{\circ}$ de janeiro a 30 de junho de 2010.

\begin{tabular}{rrrrr}
\hline CAUSAS ATRIBUÍDAS & FEM & MASC & \multicolumn{1}{c}{ TOTAL } \\
\hline HIPERBILIRRUBINEMIA & 88 & 140 & 228 \\
BAIXO PESO OU PREMATURIDADE & 77 & 115 & 192 \\
MÁ FORMAÇĀO CONGENITA & 20 & 27 & 47 \\
INFECÇÃO CONGENITA & 19 & 20 & 39 \\
APGAR 5 MIN $<7_{7}$ & 8 & 10 & 18 \\
MÃE DEPENDENTE QUIMICA & 4 & 12 & 16 \\
MÃE ADOLESCENTE E AUSÊNCIA DE VINCULO MÃE FILHO & 6 & 3 & 9 \\
HIPOGLICEMIA NEONATAL & 4 & 2 & 6 \\
MÃE COM DISTURBIO PSIQUIÁTRICO & 1 & 1 & 2 \\
\hline
\end{tabular}

Quanto às causas das inscrições dos recém-nascidos, tivemos que a maior proporção se deveu à Hiperbilirrubinemia e Baixo peso ou prematuridade. Em relação à hiperbilirrubinemia discutiu-se, quando da definição dos critérios de crianças de risco, se este deveria realmente ser adicionado, por se tratar de patologia frequente e com ótima evolução na maior parte dos casos. Porém, houve consenso quanto à importância de uma visita domiciliar precoce e de uma avaliação nos primeiros dias de vida na Unidade Básica de Saúde, garantindo assim um adequado seguimento e a prevenção das sequelas que ocorrem nos casos que não apresentam boa evolução.

Para a situação de risco Baixo peso ou Prematuridade, tivemos a inscrição de 192 crianças com esta condição. Durante a análise do banco de dados, verificamos 138 crianças com peso inferior a 2500 gramas e 138 crianças com idade gestacional inferior a 37 semanas. Porém, por se tratarem de condições distintas e de ocorrência 
nem sempre concomitante, podemos aceitar o fato de ser maior o número de inscritos com a condição Baixo peso ou Prematuridade.

A ocorrência desta condição em relação ao número total de recém-nascidos resultou em $43,9 \%$ das inscrições no projeto. Fica difícil avaliar o verdadeiro impacto desta condição, pois não se dispõe ainda do número oficial do total de nascidos vivos no primeiro semestre de 2010, filhos de mães residentes em Diadema. Se realizarmos um cálculo sobre o número de partos realizados nesse período, de gestantes residentes no município (1856 partos), com a exclusão dos natimortos (em torno de $2 \%$ do total de partos para o ano de 2009 ), teremos um total estimado de 1.819 recém-nascidos vivos, e chegaremos a um número de $7,58 \%$ de baixo peso e de $7,58 \%$ para prematuridade. Temos que a ocorrência de Baixo peso no total de nascimentos foi da ordem de 9,36\% para o ano de 2007 em Diadema, com um número de 630 recém-nascidos de baixo peso para um total de 6733 nascidos vivos (DATASUS, 2010). E para a prematuridade, neste mesmo ano, encontramos uma percentagem de $7,9 \%$ sobre o total de nascidos vivos. Esta comparação de dados vem demonstrar o grau da captação dos recém-nascidos com estas características pelo sistema, porém ainda não nos permite inferir o grau de eficiência.

Para o item Má formação congênita, temos o dado de 38 ocorrências citadas no SINASC (Sistema de Informações de Nascidos Vivos do DATASUS), o que implica em uma incidência de $0,56 \%$, para o ano de 2007 , em Diadema. Para o período de janeiro a junho de 2010 , tivemos 47 inscrições com esta ocorrência, o que implica em uma incidência de $2,58 \%$, demonstrando uma melhor captação desse dado por nosso sistema. 
Quando se avaliou o quesito Apgar menor que sete no quinto minuto, obteve-se que para a nossa amostra houve a ocorrência deste fato em $1,0 \%$ dos recém-nascidos, enquanto que em 2007 tivemos essa ocorrência relatada em 2,06\% do total dos nascidos vivos. Aqui podemos pensar em uma melhoria nas condições de nascimento das crianças ou uma falha no apontamento desta avaliação no sistema.

Em relação à variável sexo dos recém-nascidos, verificou-se que é maior o número de crianças do sexo masculino inscritas em comparação com as do feminino. Apenas para três causas de inscrição é que não se observou essa característica, que são: hipoglicemia neonatal, mãe com distúrbio psiquiátrico e mãe adolescente e com ausência de vínculo mãe-filho. Em termos percentuais tivemos que para as inscrições dos Berçários, 58,35\% foram para crianças do sexo masculino. Pelos dados do Datasus, para nascidos de mães residentes em Diadema, nos anos de 2006 e 2007, $51,2 \%$ e $50,0 \%$ dos recém-nascidos pertenciam ao sexo masculino, respectivamente. Retomaremos a discussão desta informação quando da análise da inscrição de menores de um ano de idade pós alta hospitalar.

Para Baixo Peso, tivemos com esta causa um percentual de $58,42 \%$ de recémnascidos do sexo masculino em relação ao total, discordando do fato de que meninas apresentam pesos, ao nascimento, inferiores aos dos meninos (SIQUEIRA et al, 1988). 
Tabela 7. Distribuição do número e percentagem dos recém-nascidos inscritos segundo peso de nascimento, Diadema, 1. ${ }^{\circ}$ de janeiro a 30 de junho de 2010.

\begin{tabular}{r|ccc}
\hline & PESO (g) & N. $^{\circ}$ & $\%$ \\
\hline 725 & $-1000 \mathrm{~g}$ & 2 & $0,46 \%$ \\
1000 & $-1500 \mathrm{~g}$ & 17 & $3,89 \%$ \\
1500 & $-2000 \mathrm{~g}$ & 29 & $6,64 \%$ \\
2000 & $-2500 \mathrm{~g}$ & 90 & $20,59 \%$ \\
2500 & $-3500 \mathrm{~g}$ & 201 & $46,00 \%$ \\
3500 & $-14715 \mathrm{~g}$ & 98 & $22,43 \%$ \\
\hline \multicolumn{2}{l}{ Total } & $\mathbf{4 3 7}$ & $\mathbf{1 0 0 , 0 0 \%}$ \\
\hline
\end{tabular}

Verificamos assim que $31,56 \%$ dos recém-nascidos avaliados tinham peso inferior a $2500 \mathrm{~g}$.

Nem todos os recém-nascidos inscritos tiveram seus comprimentos inseridos no sistema informatizado, resultando em um total de 391 crianças com valores apontados.

Tabela 8. Distribuição do número e percentagem dos recém-nascidos inscritos segundo comprimento ao nascimento, Diadema, $1 .^{\circ}$ de janeiro a 30 de junho de 2010.

\begin{tabular}{|c|c|c|c|}
\hline \multicolumn{2}{|c|}{ Comprimento $(\mathrm{cm})$} & \multirow{2}{*}{$\frac{\text { N. }^{\circ}}{1}$} & \multirow{2}{*}{$\begin{array}{c}\% \\
0,26 \%\end{array}$} \\
\hline$\overline{32}$ & -35 & & \\
\hline 35 & -40 & 18 & $4,60 \%$ \\
\hline 40 & -45 & 75 & $19,18 \%$ \\
\hline & -50 & 221 & $56,52 \%$ \\
\hline 50 & \begin{tabular}{l|l}
-153 \\
\end{tabular} & 76 & $19,44 \%$ \\
\hline \multicolumn{2}{|c|}{ Total } & 391 & $100,00 \%$ \\
\hline
\end{tabular}

Nem todos os recém-nascidos inscritos tiveram as idades gestacionais maternas inseridas no sistema informatizado, resultando em um total de 406 crianças com valores anotados. 
Tabela 9. Distribuição do número e percentagem dos recém-nascidos inscritos segundo a idade gestacional materna, Diadema, $1 .^{\circ}$ de janeiro a 30 de junho de 2010.

\begin{tabular}{lcc}
\hline Idade Gestacional Materna (semanas) & N. $^{0^{2}}$ & $\%$ \\
\hline $26 \mid-30 \mathrm{sem}$ & 15 & $3,69 \%$ \\
$30 \mid-35 \mathrm{sem}$ & 62 & $15,27 \%$ \\
$35 \mid-37 \mathrm{sem}$ & 61 & $15,02 \%$ \\
$37 \mid-40 \mathrm{sem}$ & 179 & $44,09 \%$ \\
$40|-| 42 \mathrm{sem}$ & 89 & $21,92 \%$ \\
\hline Total & $\mathbf{4 0 6}$ & $100,00 \%$ \\
\hline
\end{tabular}

Verificamos que $34 \%$ dos recém-nascidos avaliados tinham idade gestacional materna de até 37 semanas.

Selecionando as crianças com Idade Gestacional igual ou superior a 37 semanas, encontramos os valores para peso dos recém-nascidos:

Tabela 10. Distribuição do número e percentagem de recém-nascidos inscritos com idade gestacional referida igual ou superior a 37 semanas, segundo peso. Diadema, $1 .^{\circ}$ de janeiro a 30 de junho de 2010.

\begin{tabular}{l|ccc}
\hline \multicolumn{2}{c}{ PESO (g) } & N. $^{\mathbf{}^{2}}$ & \% \\
\hline 1325 & $-2500 \mathrm{~g}$ & 43 & $16,04 \%$ \\
2500 & $-14570 \mathrm{~g}$ & 225 & $83,96 \%$ \\
\hline Total & $\mathbf{2 6 8}$ & $\mathbf{1 0 0 , 0 0 \%}$ \\
\hline
\end{tabular}

Ainda em relação à questão do Baixo peso, é importante avaliarmos a magnitude da situação Pequeno para a Idade Gestacional (PIG), e para tal utilizamos o critério simplificado de Almeida, (ALMEIDA, 1995) - recém-nascidos de termo, acima de 37 semanas e com peso inferior a $2500 \mathrm{~g}$. Assim, encontramos um total de 43 crianças nesta condição, com uma porcentagem de $16,04 \%$ da nossa amostra de 
recém-nascidos a termo. Porém, por se tratar de crianças em situação de risco, isso também não nos permite inferir a adequada proporção da ocorrência da condição PIG no município, no período estudado. $\mathrm{Na}$ avaliação dos dados disponibilizados pelo Datasus e referentes ao ano de 2007 , encontramos a percentagem de $4,9 \%$ de recémnascidos PIG, o que é compatível com os dados encontrados por RAGONESI em 1993 para o município de São Paulo.

Para a avaliação do comprimento ao nascimento, realizou-se um comparativo com a idade gestacional materna referida no sistema, e assim obteve-se o gráfico a seguir.

Gráfico 1.

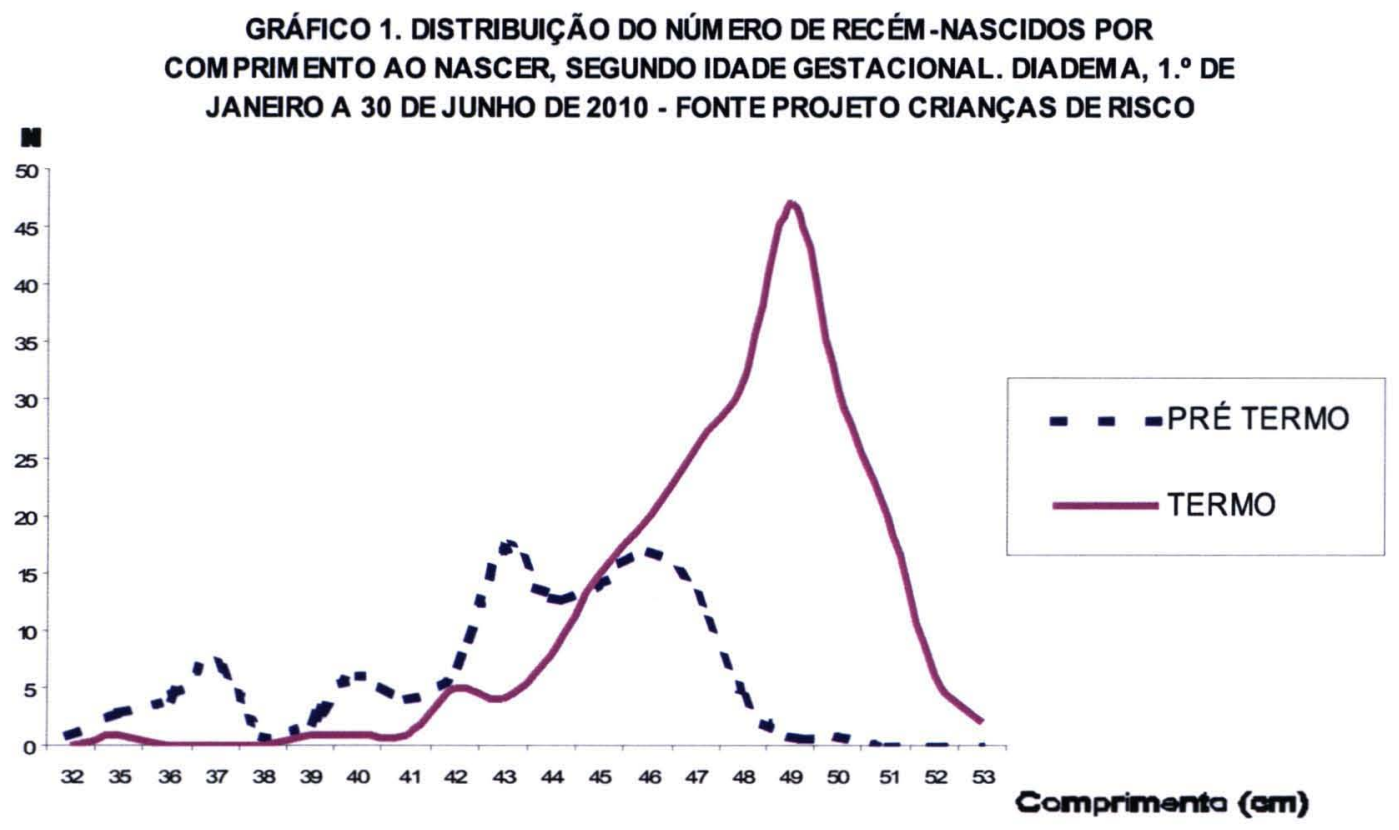


Em relação ao comprimento dos recém-nascidos, temos que $75,96 \%$ se situam na faixa de 45 a $53 \mathrm{~cm}$. O gráfico 1 reproduz o esperado, com crianças pré-termo com menores comprimentos do que as de termo.

Quanto às crianças inscritas no projeto por "pós-alta hospitalar", quanto ao sexo, temos a seguinte distribuição:

Tabela 11. Distribuição do número de crianças inscritas na condição de "pós-alta" hospitalar, segundo sexo, Diadema, $1^{\circ}$ de janeiro a 30 de junho de 2010.

\begin{tabular}{lccc}
\hline MOTIVO DA INCLUSÃO & FEM & MASC & TOTAL \\
\hline PÓS ALTA CLÍNICA & 76 & 141 & $\mathbf{2 1 7}$ \\
PÓS ALTA CIRÚRGICA & 1 & 1 & $\mathbf{2}$ \\
\hline TOTAL PÓS ALTA HOSPITALAR & $\mathbf{7 7}$ & $\mathbf{1 4 2}$ & $\mathbf{2 1 9}$ \\
\hline
\end{tabular}

Verificamos que nas inclusões pelo motivo pós-alta hospitalar, encontramos que $64,8 \%$ se referem a crianças do sexo masculino.

Complementando esta informação, temos a tabela a seguir: 
Tabela 12. Distribuição das internações de crianças menores de um ano de idade, residentes em Diadema, segundo sexo, de 2005 a 2008. Fonte: Ministério da Saúde. Sistema de Informações Hospitalares do SUS (SIH/SUS).

\begin{tabular}{|c|c|c|c|c|c|}
\hline \multirow[t]{2}{*}{ Ano } & \multicolumn{3}{|c|}{ Sexo } & \multirow[b]{2}{*}{$\%$} & \multirow[b]{2}{*}{ Total } \\
\hline & Masc & $\%$ & Fem & & \\
\hline 2005 & 659 & 55,01 & 539 & 44,99 & 1198 \\
\hline 2006 & 776 & 56,98 & 586 & 43,02 & 1362 \\
\hline 2007 & 1055 & 56,21 & 815 & 43,79 & 1870 \\
\hline 2008 & 1012 & 55,70 & 805 & 44,30 & 1817 \\
\hline Total & 3502 & 56,06 & 2745 & 43,94 & 6247 \\
\hline
\end{tabular}

Por esta série histórica, podemos afïrmar que a internação dos meninos vem ocorrendo em maior percentagem, e complementando esta informação, temos os dados referentes ao período de nosso estudo:

Tabela 13. Distribuição das internações de crianças menores de um ano de idade, segundo sexo, em residentes em Diadema, de janeiro a junho de 2010. Fonte: Ministério da Saúde. Sistema de Informações Hospitalares do SUS (SIH/SUS).

\begin{tabular}{lcc}
\multicolumn{3}{c}{$\mathbf{N}^{\circ}$ de } \\
Sexo & internaçōes & $\%$ \\
\hline Masc & 637 & 57,85 \\
Fem & 464 & 42,14 \\
\hline Total & $\mathbf{1 1 0 1}$ & $\mathbf{1 0 0 , 0 0}$
\end{tabular}

Assim, pode-se constatar dois fatos:

- o número de crianças menores de 1 ano de idade inscritas no projeto foi menor do que o número de internações ocorridas no período, (219 inscrições para 1101 internações de menores de 1 ano de idade, ou seja, 19,9\% do total) 
- dentre as inscritas no projeto, a porcentagem das do sexo masculino $(64,8 \%)$ foi maior do que a do total das internadas deste mesmo sexo $(57,85 \%)$, neste período, pelos dados do DataSus para Diadema,

Complementando estas informações, devemos analisar o gráfico a seguir que trata da evolução da Mortalidade Infantil por sexo, em Diadema.

\section{Gráfico 2.}

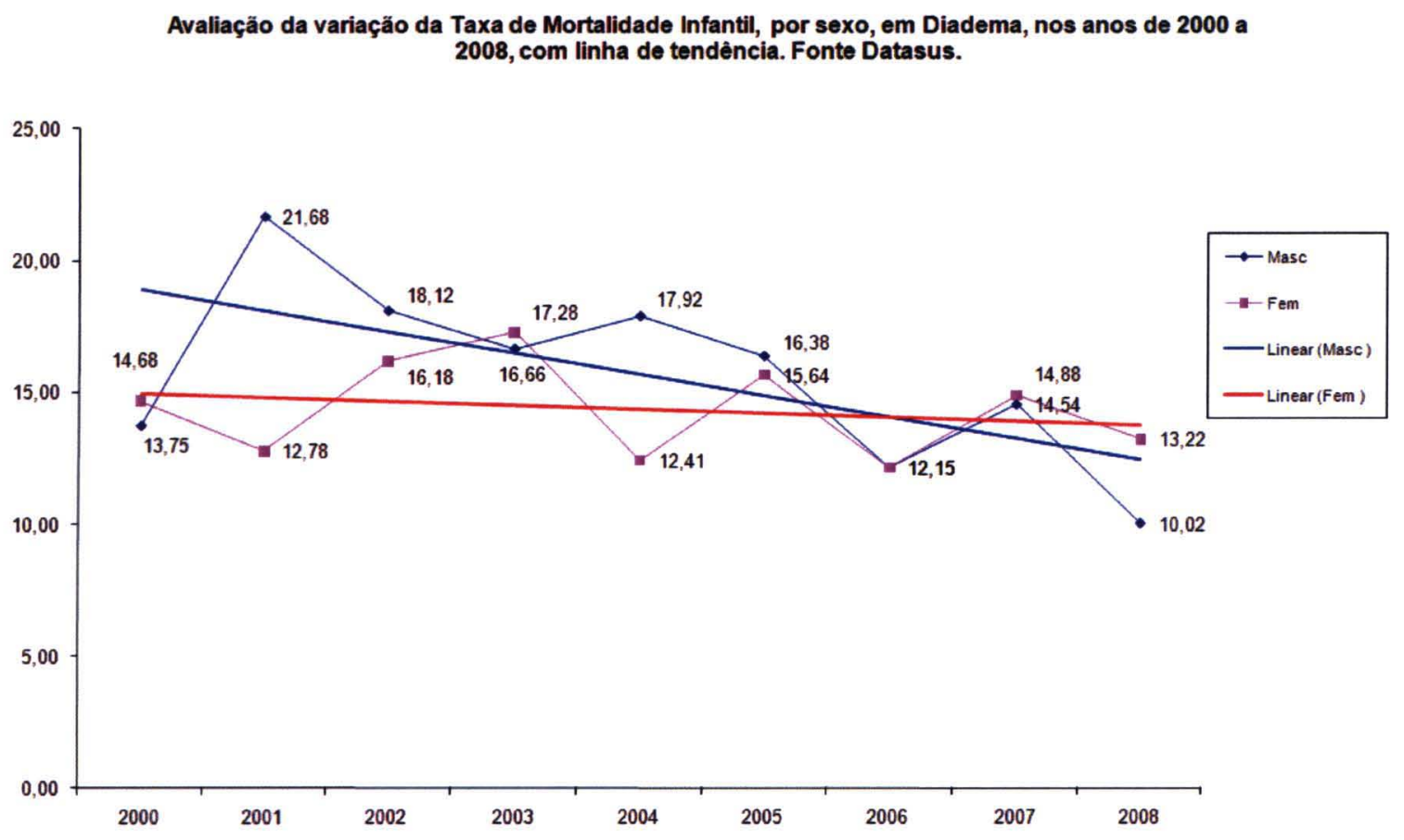

A partir deste gráfico pode-se constatar que em Diadema tem-se uma queda da mortalidade infantil para o sexo masculino mais acentuada do que para o feminino, o que nos permite pensar em três hipóteses:

- os serviços de saúde se preocupam mais com os recém nascidos do sexo masculino, o que justificaria o maior número de inscrições para este sexo no projeto, 
tanto para os recém-nascidos das Maternidades quanto para os menores de um ano egressos das enfermarias de Pediatria,

- os pais (ou responsáveis) atualmente cuidam mais dos recém-nascidos do sexo masculino, o que justificaria a maior taxa de internação e a diminuição da mortalidade,

- as crianças dos sexo masculino apresentaram uma maior taxa de morbidade, o que justificaria sua maior taxa de internação, porém pela qualidade do atendimento que lhes foi prestado, apresentaram decréscimo da taxa de mortalidade.

Avaliando-se os dados de internação para todo o território nacional, por sexo, para crianças menores de um ano, temos:

Tabela 14. Distribuição do número de internações em menores de um ano de idade, ocorridas no Brasil no periodo de 2008, 2009 e de janeiro a junho de 2010 , segundo sexo. Fonte: Ministério da Saúde. Sistema de Informações Hospitalares do SUS (SIH/SUS).

\begin{tabular}{cccccc} 
Ano & \multicolumn{5}{c}{ Sexo } \\
& Masc & $\boldsymbol{\%}$ & Fem & $\%$ & Total \\
\hline $\mathbf{2 0 0 8}$ & 309939 & 55,30 & 250447 & 44,70 & 560386 \\
$\mathbf{2 0 0 9}$ & 321834 & 55,30 & 259970 & 44,70 & 581804 \\
$\mathbf{2 0 1 0}$ & 164334 & 55,20 & 133144 & 44,80 & 297478 \\
\hline Total & $\mathbf{7 9 6 1 0 7}$ & $\mathbf{5 5 , 3 0}$ & $\mathbf{6 4 3 5 6 1}$ & $\mathbf{4 4 , 7 0}$ & $\mathbf{1 4 3 9 6 6 8}$
\end{tabular}

Estes dados demonstram que a ocorrência de maior porcentagem de internação de crianças do sexo masculino no país vem ocorrendo praticamente sem oscilações de 2008 em diante. Comparativamente, temos que para o município de Diadema, esta 
está ligeiramente acima da proporção nacional, e que no sistema informatizado, muito além do encontrado para o município.

Pelas informações aqui levantadas, tanto as provenientes do DATASUS, quanto as do sistema informatizado, tem-se que as três hipóteses são plausíveis sobre o que de fato tem ocorrido no município de Diadema.

Apesar de realidades bem distintas, temos em países como a China e a Índia uma maior preocupação nos cuidados gerais dos recém-nascidos do sexo masculino, abrangendo aqui a atenção a saúde. Isso se reflete em uma diminuição da taxa de mortalidade infantil para este sexo e em um aumento da população masculina adulta. Apesar de que muitos fatores estão envolvidos nestes países (culturais, religiosos, nível de educação), e com o cuidado para as diferentes proporções lá e aqui encontradas, a constatação desse fato em nosso meio nos remete a necessidade de uma maior avaliação do que ocorre em relação aos cuidados de saúde por gênero no Brasil.

Encontra-se na literatura dados sobre a maior taxa de morbidade que os recém-nascidos do sexo masculino apresentam nos serviços de saúde, principalmente quando estes têm Baixo peso (STEVENSON et al, 2000). As patologias que, em relação ao sexo feminino, mais os acometem, são principalmente as do trato respiratório e as infecciosas do trato urinário.

A seguir, analisaremos as causas das internações das crianças menores de um ano inscritas no projeto. 
Tabela 15. Distribuição do número e percentagem das causas de internação das crianças inscritas na condição "pós-alta" hospitalar, Diadema, 1. de janeiro a 30 de junho de 2010.

\begin{tabular}{|c|c|c|}
\hline Causas de Internação & N. ${ }^{\circ}$ & $\%$ \\
\hline BRONQUIOLITE & 65 & $29,68 \%$ \\
\hline BCP & 21 & $9,59 \%$ \\
\hline FEBRE A ESCLARECER & 18 & $8,22 \%$ \\
\hline BE & 15 & $6,85 \%$ \\
\hline IGNORADA & 13 & $5,94 \%$ \\
\hline DDA & 9 & $4,11 \%$ \\
\hline$B C P+B E$ & 7 & $3,20 \%$ \\
\hline$B E+B C P$ & 7 & $3,20 \%$ \\
\hline BRONQUIOLITE+BE & 6 & $2,74 \%$ \\
\hline LARINGITE & 6 & $2,74 \%$ \\
\hline BRONQUIOLITE + BCP & 4 & $1,83 \%$ \\
\hline CONVULSAO FEBRIL & 4 & $1,83 \%$ \\
\hline BE+IVAS & 3 & $1,37 \%$ \\
\hline DDA + DESIDRATAÇĀO & 3 & $1,37 \%$ \\
\hline CRISE CONVULSIVA & 2 & $0,91 \%$ \\
\hline DISPEPSIA AGUDA & 2 & $0,91 \%$ \\
\hline DOR ABDOMINAL & 2 & $0,91 \%$ \\
\hline IMPETIGO & 2 & $0,91 \%$ \\
\hline ITU & 2 & $0,91 \%$ \\
\hline RGE & 2 & $0,91 \%$ \\
\hline SINDROME GRIPAL & 2 & $0,91 \%$ \\
\hline ABSCESSO MAMÁRIO & 1 & $0,46 \%$ \\
\hline$B C P$ + BE + DDA & 1 & $0,46 \%$ \\
\hline$B C P+B E+O T I T E$ & 1 & $0,46 \%$ \\
\hline BRONQUIOLITE + IVAS & 1 & $0,46 \%$ \\
\hline CARDIOPATIA & 1 & $0,46 \%$ \\
\hline CELULITE PERIORBITAL & 1 & $0,46 \%$ \\
\hline DDA+BCP & 1 & $0,46 \%$ \\
\hline ABSCESSO PERIANAL & 1 & $0,46 \%$ \\
\hline ENTERORRAGIA & 1 & $0,46 \%$ \\
\hline ESTOMATITE & 1 & $0,46 \%$ \\
\hline EXANTEMA & 1 & $0,46 \%$ \\
\hline FRATURA PARIETAL DIREITA (CIRÜRGICO) & 1 & $0,46 \%$ \\
\hline HIPOSPADIA DISTAL (CIRÚRGICO) & 1 & $0,46 \%$ \\
\hline IRA & 1 & $0,46 \%$ \\
\hline IRRITABILIDADE & 1 & $0,46 \%$ \\
\hline ITU + DDA & 1 & $0,46 \%$ \\
\hline MENIGITE BACTERIANA & 1 & $0,46 \%$ \\
\hline MENINGITE & 1 & $0,46 \%$ \\
\hline NEFROPATIA & 1 & $0,46 \%$ \\
\hline RGE+ BE & 1 & $0,46 \%$ \\
\hline SEPSE & 1 & $0,46 \%$ \\
\hline TCE & 1 & $0,46 \%$ \\
\hline TCE+ABCESSO CRÂNIO ENCEFALICO & 1 & $0,46 \%$ \\
\hline VARICELA & 1 & $0,46 \%$ \\
\hline Total & 219 & $100,00 \%$ \\
\hline
\end{tabular}


Em relação aos motivos que levaram as crianças a serem internadas no período, temos que $64,38 \%$ das causas se deveram a patologias respiratórias, demonstrando o elevado peso que estas morbidades representam para essa população menor de um ano de idade. 


\subsection{RELATIVAS AO ACOMPANHAMENTO DESTAS CRIANÇAS}

Os resultados a seguir dizem respeito ao número de consultas de acompanhamento nas Unidades Básicas de Saúde e Ambulatório de prematuros, realizadas para as crianças inscritas no periodo do estudo. Devemos lembrar que as crianças matriculadas no início do período terão a oportunidade de realizar um maior número de acompanhamentos do que as crianças inscritas ao final deste.

Tabela 16. Distribuição do número e percentagem de crianças segundo o número de acompanhamentos realizados. Diadema, $1 .^{\circ}$ de janeiro a 30 de junho de 2010.

\begin{tabular}{ccc}
\hline $\begin{array}{c}\text { N. } \\
{ }^{\circ} \text { de acompanhamentos } \\
\text { realizados }\end{array}$ & $\mathbf{N .}^{\circ}$ de crianças & Porcentagem \\
\hline 0 & 261 & $41,04 \%$ \\
1 & 122 & $19,18 \%$ \\
2 & 80 & $12,58 \%$ \\
3 & 45 & $7,08 \%$ \\
4 & 39 & $6,13 \%$ \\
5 & 29 & $4,56 \%$ \\
6 & 26 & $4,09 \%$ \\
7 & 17 & $2,67 \%$ \\
8 & 5 & $0,79 \%$ \\
9 & 5 & $0,79 \%$ \\
10 & 1 & $0,16 \%$ \\
11 & 5 & $0,79 \%$ \\
13 & 1 & $0,16 \%$ \\
\hline Total & $\mathbf{1 3 6}$ & $\mathbf{1 0 0 , 0 0 \%}$ \\
\hline
\end{tabular}


No cômputo geral foram realizadas 1156 consultas de acompanhamento, com uma média de 1,81 consulta por criança e uma mediana de 1,46 consulta.

No que concerne às consultas de acompanhamento das crianças, verificamos que elas ficaram muito abaixo do esperado, e nos preocupa o fato de que $41,04 \%$ das crianças não receberam nenhum tipo de consulta. Podemos pensar em três justificativas para esta baixa porcentagem de acompanhamento:

- não houve tempo hábil para a coleta de informações da criança, (observouse que 75 inscrições foram realizadas no mês de junho),

- o domicílio referido na internação não foi encontrado, fato que ocorre com certa freqüência, motivado pelo medo que a população manifesta em referir seu correto endereço, e que diz respeito à rejeição da internação por residir em outro município,

- não se digitou, nas Unidades Básicas de Saúde, a totalidade das consultas de acompanhamento.

Aplicando um modelo matemático simples, e detalhado a seguir, buscou-se avaliar o encontrado na Tabela 17.

Tabela 17. Modelo matemático simplificado para avaliação das consultas de acompanhamento.

\begin{tabular}{lcc} 
Mês & $\begin{array}{c}\mathbf{N} .^{\circ} \text { de crianças } \\
\text { inscritas }\end{array}$ & $\begin{array}{l}\mathbf{N}^{\circ} \text { de acompanhamentos realizados } \\
\text { no período de janeiro a junho }\end{array}$ \\
\hline Janeiro & 1 & 5 \\
Fevereiro & 1 & 4 \\
Março & 1 & 3 \\
Abril & 1 & 2 \\
Maio & 1 & 1 \\
Junho & 1 & 0 \\
\hline Total & 6 & 15
\end{tabular}


Dentro deste modelo, em que temos uma consulta mensal por criança inscrita, encontramos uma média de 2,5 consultas de acompanhamentos por criança e uma mediana de 2,5 consultas. Esses números são superiores aos encontrados, que foram de uma média de 1,81 consulta por criança e uma mediana de 1,46 consulta, e assim temos que estas crianças não estão sendo adequadamente acompanhadas, pois não estão tendo, minimamente, uma periodicidade mensal em seus agendamentos. Cumpre ressaltar, porém, que o modelo não computou as possíveis altas do projeto, $o$ que nos levaria a uma diferença menor do que a estimada acima.

Avaliando-se a porcentagem do sexo das crianças acompanhadas, encontramos a tabela a seguir:

Tabela 18. Percentagem de crianças segundo o número de acompanhamentos realizados e sexo. Diadema, $1 .^{\circ}$ de janeiro a 30 de junho de 2010.

\begin{tabular}{ccc}
\hline $\begin{array}{c}\text { N. de acompanhamentos } \\
\text { realizados }\end{array}$ & $\begin{array}{l}\text { \% sexo } \\
\text { Fem }\end{array}$ & $\begin{array}{c}\text { \% sexo } \\
\text { Masc }\end{array}$ \\
\hline 0 & $38,80 \%$ & $42,49 \%$ \\
1 & $16,00 \%$ & $21,24 \%$ \\
2 & $13,20 \%$ & $12,18 \%$ \\
3 & $8,80 \%$ & $5,96 \%$ \\
4 & $7,20 \%$ & $5,44 \%$ \\
5 & $5,20 \%$ & $4,15 \%$ \\
6 & $5,20 \%$ & $3,37 \%$ \\
7 & $2,00 \%$ & $3,11 \%$ \\
8 & $1,20 \%$ & $0,52 \%$ \\
9 & $1,20 \%$ & $0,52 \%$ \\
10 & $0,40 \%$ & $0,00 \%$ \\
11 & $0,80 \%$ & $0,78 \%$ \\
13 & $0,00 \%$ & $0,26 \%$ \\
\hline Total & $\mathbf{1 0 0 , 0 0 \%}$ & $\mathbf{1 0 0 , 0 0 \%}$ \\
\hline
\end{tabular}

Temos assim que $45,20 \%$ das crianças do sexo feminino realizaram 2 ou mais acompanhamentos para um total de $36,27 \%$ do sexo masculino, demonstrando assim 
uma maior cuidado dos responsáveis no acompanhamento das crianças do sexo feminino. 


\subsection{RELATIVAS ÀS ALTAS DAS CRIANÇAS INSCRITAS}

Avaliaram-se as altas das crianças inscritas no projeto no periodo de $1 .^{\circ}$ de janeiro a 30 de junho de 2010 , e cujas altas ocorreram dentro deste mesmo período.

Tabela 19. Distribuição do número e percentagem de crianças que tiveram alta do projeto segundo motivos. Diadema, $1 .^{\circ}$ de janeiro a 30 de junho de 2010.

\begin{tabular}{lcc}
\hline Motivo da alta & N. & $\%$ \\
\hline OUTROS & 38 & $36,50 \%$ \\
SITUAÇÃO DE RISCO AFASTADA & 36 & $34,60 \%$ \\
MAIOR DE 1 ANO & 17 & $16,30 \%$ \\
MUDANÇA DE MUNICÍPIO & 13 & $12,50 \%$ \\
\hline Total & $\mathbf{1 0 4}$ & $\mathbf{1 0 0 , 0 0 \%}$ \\
\hline
\end{tabular}

A média de permanência destas crianças no projeto foi de 51 dias e a mediana de 41 dias.

Em relação às altas, observou-se que $16,35 \%$ das crianças inscritas no projeto receberam alta no periodo aqui considerado. Concluímos assim que a maior parte delas seguirá em acompanhamento até completar 1 ano de idade ou ter outra condição de alta satisfeita.

Uma falha observada foi a disponibilização da opção "Outros", pois esta refletiu a maior parte das altas observadas. Tal opção não possibilitou a compreensão do que realmente ocorreu com estas crianças.

Não se observou, como motivo de saída do projeto, a ocorrência de óbitos dentre as crianças inscritas e avaliadas neste período. 


\section{CONCLUSÃO}

A necessidade de se utilizar corretamente os recursos disponíveis para o atendimento da população nos orienta para um trabalho com prioridades, buscando avaliar adequadamente os mais necessitados e dispensando uma adequada atenção a estes. A partir dessa premissa, disponibilizou-se pela Internet uma nova ferramenta para o cadastro e acompanhamento de crianças em situações de risco, facilitando assim o acesso a todos os profissionais da rede de saúde e agilizando as visitas domiciliares e o agendamento destas crianças. Pode-se avaliar, com este estudo, como o sistema foi utilizado no município de Diadema, no período definido. Verificou-se que a inscrição dos recém-nascidos provenientes dos berçários se deu de maneira eficiente, o mesmo, porém, não ocorreu para as crianças menores de um ano de idade, egressas de enfermarias de pediatria, já que o preconizado é de que todas deveriam ter sido inscritas quando da alta hospitalar. $\mathrm{O}$ acompanhamento de todas as crianças também ficou abaixo do esperado.

Quanto aos critérios de inclusão e de saída do sistema, verificou-se a necessidade de uma maior discussão entre os profissionais de saúde do município acerca de uma melhor definição de alguns critérios, com a sugestão da separação de Baixo peso ou prematuridade, para melhor compreensão da magnitude que cada quesito representa para a população de recém-nascidos, e uma outra concepção para Gravidez manifestadamente indesejada, que envolva dados obtidos pela Unidade Básica de Saúde sobre o desenvolvimento da gestação. Para a saída do sistema caberia uma melhor definição do item Outros, com a sugestão do preenchimento de um campo obrigatório de explicação caso ocorra esta opção. 
Em relação às características das crianças incluídas no projeto no período do estudo, verificou-se uma maior porcentagem das do sexo masculino, com grande incidência de Hiperbilirrubinemia e Baixo peso ou prematuridade, para os provenientes dos berçários. Quanto aos menores de um ano que receberam alta hospitalar, verificou-se também uma maior porcentagem de crianças do sexo masculino, com alta incidência de patologias respiratórias no total das crianças estudadas. 


\section{CONSIDERAÇÕES FINAIS}

O sistema informatizado utilizado para o projeto Crianças de Risco foi disponibilizado para satisfazer as necessidades do município de Diadema quanto ao cadastramento e acompanhamento das crianças de risco, precisando, no entanto, de alguns ajustes, que são:

1) um plano de educação continuada dos usuários e profissionais da rede de saúde,

2) uma ação contínua de devolutiva dos dados e informações obtidas pelo sistema e por fim,

3) um projeto de implantação de um plano de gestão.

Vale ressaltar que o tipo de parto não foi disponibilizado no sistema informatizado, porém observamos que a existência desta opção nos possibilitaria importante correlação com a avaliação dos demais itens.

Verificou-se, pois, que muitas são as informações geradas, as quais, se devidamente analisadas, poderão colaborar eficientemente para o planejamento e a gestão de futuras ações de saúde nessa área. 


\section{REFERÊNCIAS}

- Abreu DMX, César CC, França EB. Relação entre as causas de morte evitáveis por atenção à saúde e a implementação do Sistema Único de Saúde no Brasil. Rev Panam Salud Publica. 2007;21(5):282-91.

- Almeida M.F. Mortalidade neonatal em Santo André. [Tese de Doutorado]. São Paulo: Faculdade de Saúde Pública da USP; 1995.

- Barros FC, Victora CG, Barros AJ, et al. The challenge of reducing neonatal mortality in middle-income countries: findings from three Brazilian birth cohorts in 1982, 1993, and 2004. The Lancet. 2005; 365: 847-54.

- Barros FC, Victora CG, Matijasevich A, et al. Preterm births, low birth weight, and intrauterine growth restriction in three birth cohorts in Southern Brazil: 1982, 1993 and 2004. Cad Saúde Pública. 2008; 24 (suppl 3): 390-98.

- Bettiol H, Rona RJ, Chinn S, Goldani M, Barbieri MA. Factors associated with preterm births in southeast Brazil: a comparison of two birth cohorts born 15 years apart. Paediatr Perinat Epidemiol. 2000; 14: 30-38.

- Bhutta ZA, Darmstadt GL, Hasan BS, Haws RA. Community-Based Interventions for Improving Perinatal and neonatal health Outcomes in Developing Countries: A Review of the Evidence. Pediatrics. 2005; 115: 519-617.

- Brasil. Constituição (1988). Constituição da República Federativa do Brasil. Brasília, DF: Senado; 1988. 
- Buss PM. Promoção da saúde e qualidade de vida. Ciênc. Saúde Coletiva. $2000 ; 5(1): 163-177$

- Departamento de Informática do SUS - DATASUS - Informações de saúde Estatísticas vitais - Mortalidade e nascidos vivos. [homepage da internet]. Brasília, c2008 [acesso em 18 set 2010]. Disponível em: www.datasus.gov.br

- Departamento de Informática do SUS - DATASUS . Pacto de atenção básica 2006. http://tabnet.datasus.gov.br/cgi/tabcgi.exe?siab/pacto2006/pacbr.def (acesso em 7 março de 2011).

- Donoso SE, Donoso DA, Vilarroel LP. Mortalidad perinatal e infantil y el bajo peso al nacer en Chile y Cuba en el periodo 1991 - 2001. Ver Chil Obstet Ginecol. 2004; 69(3): 203-208

- Duarte CMR. Equidade na Legislação: um princípio do sistema de saúde brasileiro? Rev Ciência \& Saúde Coletiva. 2000; 5(2):443-463.

- Gomes FRS, Paiva GDH, Vezzuli RVS, Luz SRC, Smalkoff. T. Plano Diretor Assistencial do Hospital Municipal de Diadema [Monografia de conclusão do curso de Formação Especifica de Gestão em Saúde]. São Paulo: Universidade Federal de São Paulo; 2008.

- Instituto Brasileiro de Geografia e Estatística - IBGE. Departamento da População e Indicadores Sociais, Evolução e perspectiva da mortalidade infantil no Brasil [documento na Internet]. Rio de Janeiro; 1999 [acesso em 28 nov 2009] Disponível em 
http://www.ibge.gov.br/home/estatistica/populacao/evolucao perspectivas_mortalida de/evolucao mortalidade.pdf

- Instituto Brasileiro de Geografia e Estatística - IBGE. Primeiros dados do censo 2010. [homepage da internet]. Rio de Janeiro, c2010 [acesso em 05 fev 2010]. Disponível em:

http://www.ibge.gov.br/censo2010/primeiros dados divulgados/index.php?uf $=35$

- Laurenti R. Mortalidade Infantil nos Estados Unidos, Suécia e Estado de São Paulo. Rev Saúde Pública. 1987; 21(3): 268-73.

- Laurenti R, Silveira MH, Siqueira AAF. Mortalidade Perinatal em São Paulo. Brasil. Rev Saúde Pública. 1975; 9: 115-24.

- Medeiros M. Princípios de Justiça na Alocação de Recursos em Saúde Rio de Janeiro. Texto para discussão do IPEA; 1999, nº 687.

- Ministério da Saúde. Saúde Brasil 2005: uma análise da situação de saúde [documento da Internet] Brasília; 2005. [acesso em 28 nov 2009] Disponível em http://portal.saude.gov.br/portal/arquivos/pdf/saude_brasil_2005.pdf

- Organização Mundial da Saúde - OMS. The World Health Report: making a difference [documento na Internet]. Genebra; 1999 [acesso em 28 nov 2009] Disponivel em www.who.int/entity/whr/1999/en/

- Ragonesi SMA. et al. Crescimento intrauterino retardado. Rev. Latinoam. Perinatol. 1993; 13: 15-46. 
- Reis DO. Características da mortalidade neonatal de residentes no município de Diadema, segundo município de ocorrência de nascimento. [dissertação de mestrado]. São Paulo: Faculdade de Saúde Pública da USP; 2000.

- Rumel D, Capistrano D, Aiello S, Koyama SM, Rosembaum W. Acurácia dos indicadores de risco do Programa de Defesa da Vida dos Lactentes em região do Estado de São Paulo, Brasil. Rev Saúde Públ 1992; 26 (1): 6-11.

- Silva AA, Barbieri MA, Bettiol H, Goldani MZ, Rona RJ. Can we explain why Brazilian babies are becoming lighter? Int J Epidemiol 2004; 33: 821-28.

- Simões CCS, Monteiro CA. Tendência secular e diferenças regionais da mortalidade infantil no Brasil. In: Monteiro CA, organizador. Velhos e novos males da saúde no Brasil: a evolução do país e de suas doenças. São Paulo: Hucitec Nupens/USP; 1995. p. 153-156.

- Siqueira AAF, Tanaka ACA, Souza MLR, Santana RM. Estudo sobre nascidos vivos em Maternidades - Peso ao Nascer, Sexo, Tipo de nascimento e filiação previdenciária. Rev. Saúde públ. 1988; 22(6): 489-493.

- Stevenson DK, Verter J, Fanaroff AA, Oh W, Ehrenkranz A, Shankaran S, et al. Sex differences in outcomes of very low birthweight infants: the newborn male disadvantage. Arch Dis Child Fetal Neonatal Ed 2000; 83: 182 - 185.

- Victora CG, Aquino EML, Lea MCl, Monteiro CA, Barros FC, Szwarcwald CL. Saúde de mães e crianças no Brasil: progressos e desafios. The Lancet. 2011; supl Brasil maio: 32-46. 
- Wallace HM, Hong JW, Ericson A. Comparison of infant mortality in the United States and Sweden. J Trop pediat. 1985; 31(4):223-8 
OF.COEP/06/10

27 de janeiro de 2010.

Prezado(a) Pesquisador(a) e Orientador(a),

o Comitê de Ética em Pesquisa da Faculdade de Saúde Pública da Universidade de São Paulo - COEP/FSP, analisou, de acordo com a Resolução N. ${ }^{\circ}$ 196/96 do Conselho Nacional de Saúde - CNS e suas complementares o protocolo de pesquisa n.0 2057, intitulado "UTILIZAÇÃo DE UMA NOVA TECNOLOGIA PARA O CADASTRO E ACOMPANHAMENTO DE CRIANCAAS DE RISCO NO MUNICÍPIO DE DIADEMA-SP", área temática GRUPO III, sob responsabilidade do(a) pesquisador(a) Edson Aguilar Perez $e$ orientação do(a) Professor(a) Arnaldo Augusto Franco de Siqueira, considerando que o projeto apresentado não se enquadra em pesquisa com seres humanos em saúde.

Cabe informar que a folha de rosto será estornada do sistema SISNEP/CONEP bem como o Certificado de Apresentação para Apreciação Ética (C.A.A.E.) gerado.

Atenciosamente,

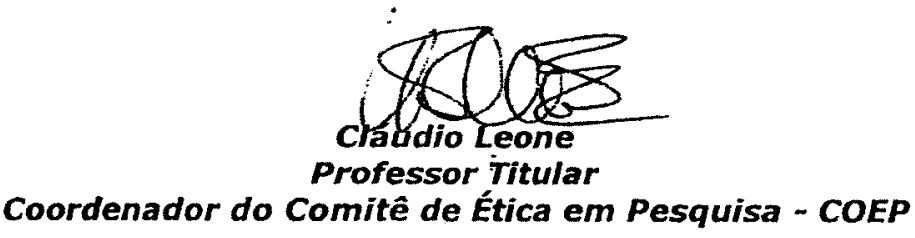

IIm. ${ }^{\circ} \mathrm{Sr}$.

Prof. Tit. Arnaldo Augusto Franco de Siqueira Departamento de Saúde Materno-Infantil Faculdade de Saúde Pública - USP

Av. Dr. Arnaldo, 715 - Assessoria Acadêmica - CEP: 01246-904 - São Paulo - SP Telefones: (55-11) 3061-7779/7742 e-mail: coep@fsp.usp.br site www.fsp.usp.br 


\section{PREFEITURA DO MUNICÍPIO DE DIADEMA SECRETARIA DA SAÚDE COORDENAÇÃO DE ATENÇÃO BÁSICA}

\section{DECLARACĨO DE AMUÂMGTA ETERMO DE.COMPROMISSO}

Declaro que conheço e cumprirei os requisitos da Res. CNS 196/96 e suas complementares. Comprometo-me a utilizar os materiais e dados coletados exclusivamente para os fins previstos no protocolo de pesquisa intitulado UTILIZAÇÃO DE UMA NOVA TECNOLOGIA PARA O CADASTRO E ACOMPANHAMENTO DE CRIANÇAS DE RISCO NO MUNICIPIO DE DIADEMA-SP.

Declaro, ainda, estar ciente da realização da pesquisa acima intitulada, nas dependências da Coordenação da Atenção Básica da Secretaria de Saúde de Diadema, e como esta instituição tem condições para o desenvolvimento deste projeto, autorizo sua execução.

Diadema, 14 de dezembro de 2009.

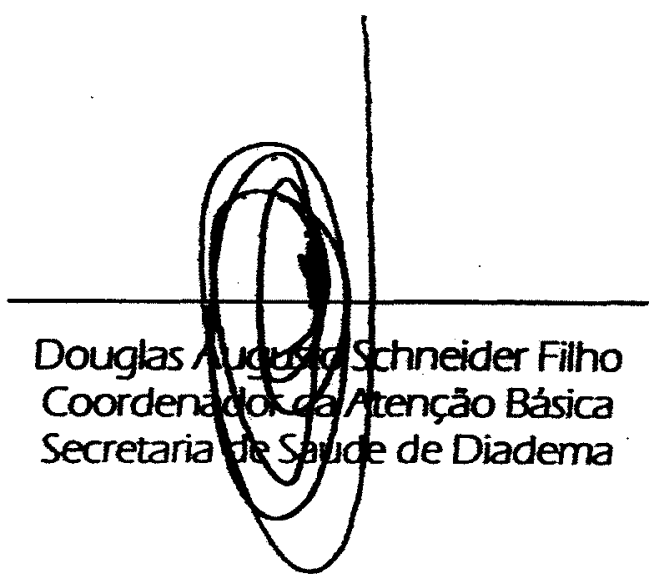




\section{Anexo 3}

\section{TELAS DO SISTEMA INFORMATIZADO DO PROJETO}

\section{CRIANÇAS DE RISCO}

Acesso: www.diadema.sp.gov.br/crianca_risco

Tela1.

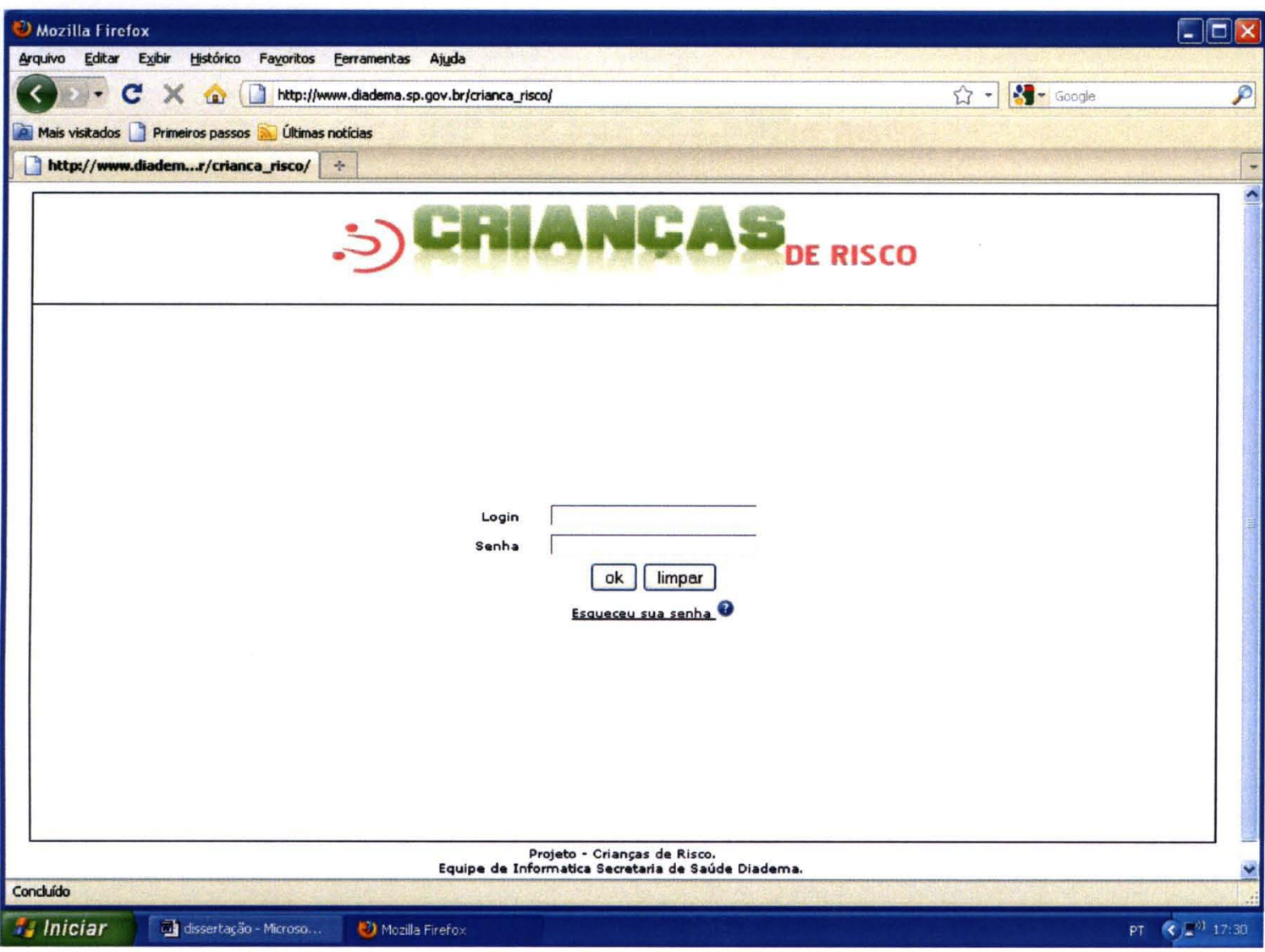


Tela 2.

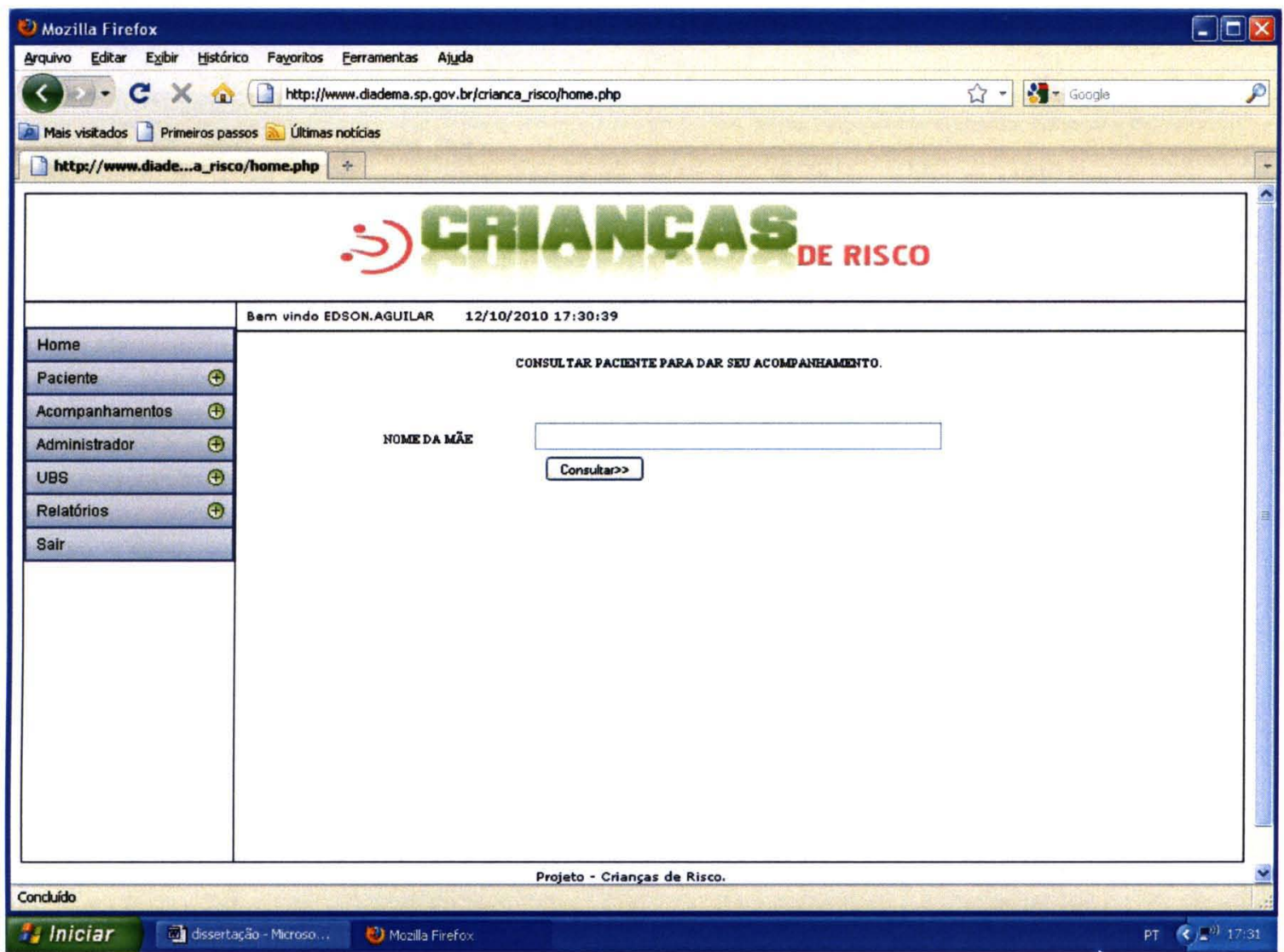


Tela3.

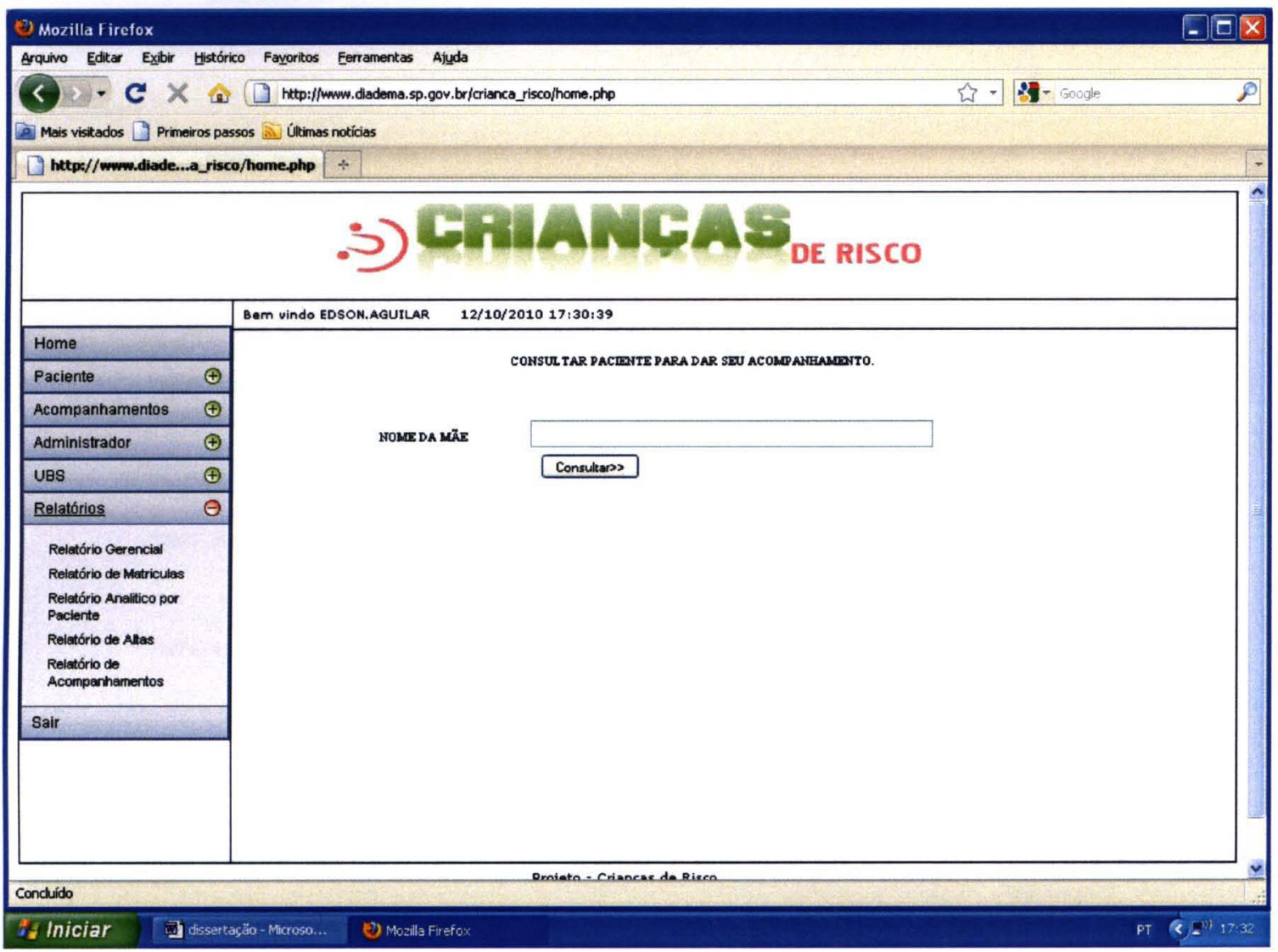




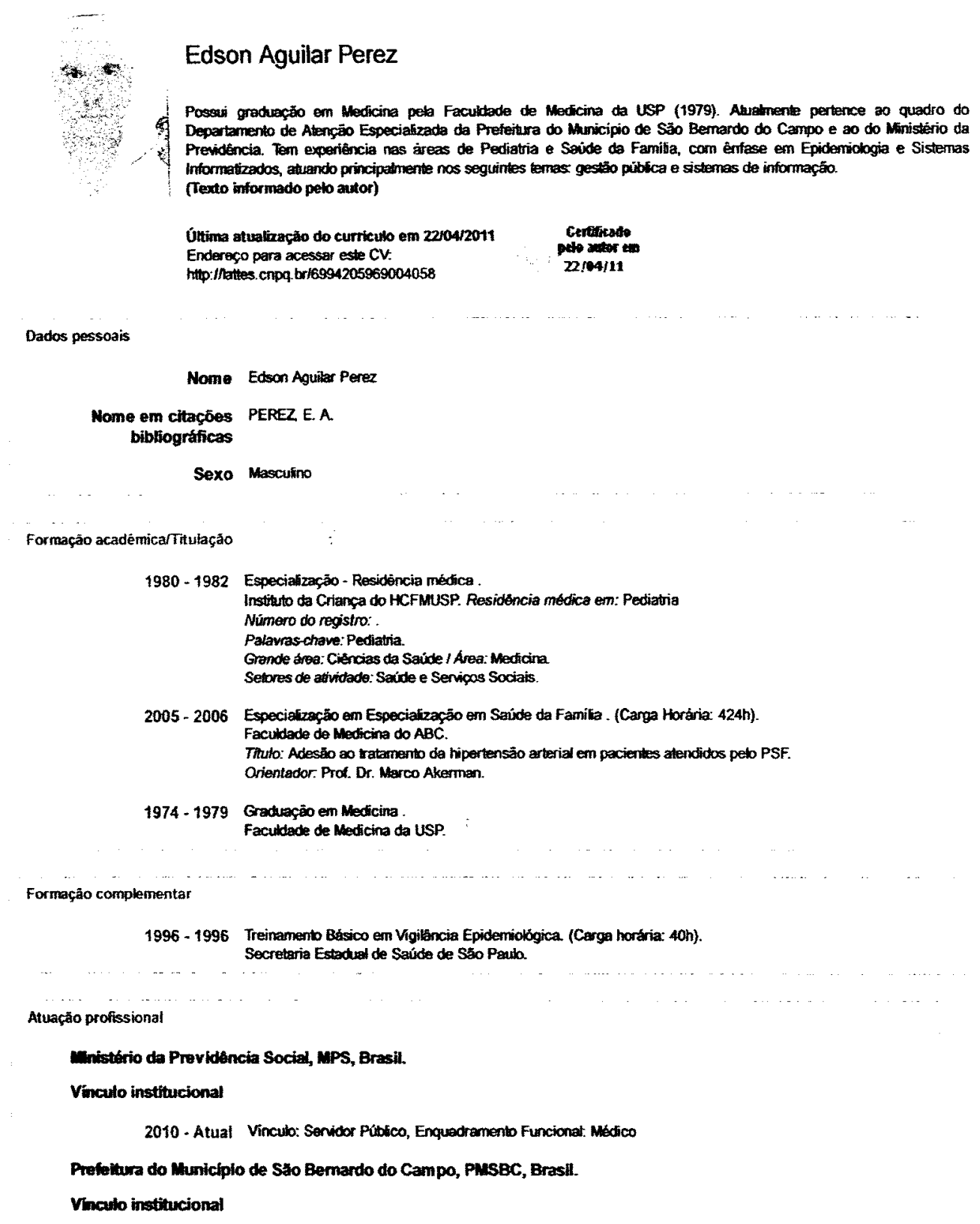

1981 - Atual Vinculo: Senvidor Público, Enquadramento Funcionat, Coordenador do SiAB, Carga horäria: 20

Áreas de atuação

1. Grande Área: Cièncias da Saúde / Área: Medicina.

Idiomas

\section{Espanhol Compreende Bem, Fab Bem, Lê Bem, Escreve Bem. \\ Ingles Compreende Bem, fala Razoavetnente, Lê Bem Escreve Razoavetnente.}

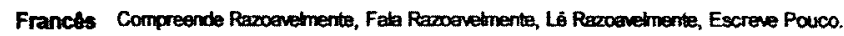




\section{Arnaldo Augusto Franco de Siqueira}

possui graduaço en Faculdade de Medicina pela Univensidade de Sảo Paulo (1966)

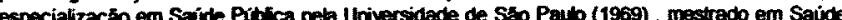

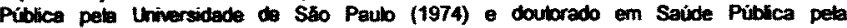

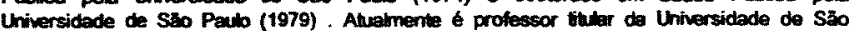
Paub. Tem experiència ma erea de Saúde Coletive, com enfase em Saúde Púticica. Aluando principatmente nos seguintes temas: ESTUDO DE UM CONUUNTO DE CCURVAS

(Texto gerado automaticanente peb aplicayso CVLattes)

Úlima atuallearion do curriculo em 28/11/2010 Endereço para acessar este CV:

hitp://hattes. cnpq br/6193792753405713

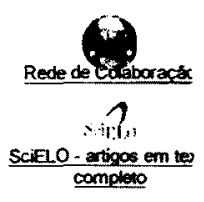

Costicado

28/11/10

Dados pessoais

Mome Arnaldo Augusto Franco de Siqueire

Nome en citaçoes SICUEIRA A. A. F.

bibllográficas

Sexo Masculino

Endereço profissional Unversidade de SÉ Pando, Faculdade de Saúde Pública.

Avenida Doutor Amatio, 715

Cerqueira Ceser

01246-904 - Sao Pauto, SP - Brasil

Tolofone: (11) 30812451 Fax (11) 30850240

UPL da Homepege: mum. Isp. usp. or

Formaçåo académicarthtulaçăo

1981 Livredocéncin

Universidade de Sáo Pauto, USP, Brasil

Thuto: Ano de oblençấ: 1981 .

1975 - 1979 Doutorado en Saude Pública (Conceito CAPES 5)

Universidade de Sâo Paulo, USP, Bras

Thuto: ESTUDO DE UM CONUUNTO DE CCURNAS ANTROPOMETIRICAS NO DIAGNOS HCO DE ESTADO

MUTROCIONWL DE GESTANTES E SUA RELAÇÃO COM O TMUANHO DO RECÉMMNASCIDO, AnO de

Obtença: 1979

Orientedor. PEDRO AUGUSTO MARCONDES DE ALMEIOA

Bolsista do(a): Fundacto de Ampero á Pesquisa do Estado de Sao Paulo.

Palavras chave: ESTUDO DE UM CONUUNTO DE CCURVAS ANTROPOMETRACAS N

Grande área: Ciéncias da Saúde I Arba: Saúde Coletiva / Subdrea: Saúde Pública.

Grande Area: Ciencias da Saide I Area: Sacide Coletiva.

Setores de afivdode. Saíde Humane.

1971 - 1974 Mestrado em Saúde Pública (Conceito CAPES 5) .

Universidade de Sá Paulo, USP, Brasil.

Thulo: Mortaidade Neonstal e Premaluridade, Ano de Ostensas: 1974.

Orientador. Cyro Ciari Júnior.

Palawas-chove: Mortaldade; Necnatat, Prematuridade.

Grande drea: Ciências da Saide / Area: Saide Colletiva / Subreo: Saide Pübica.

1969 - 1969 Especializaçio em Saide Pública

Unversidade de Sá Prato, USP, Brasit.

1960 - 1966 Greduaclo em Faculdede de Madicina

Unhersidede de SAo Paub, USP, Brasi

Atuagato profissionat

Universidade de Sso Paulo, USP, Bras:

Vinctio insthucional

2002 - Atual Vinculo: Senidor Publico. Enquadramento Funcionat. Protessor flular, Carga horária: 0

Outras informaçōes Orientador na Pós-Grackeckio 